\title{
A Novel Hybrid Method based on Krill Herd and Cuckoo Search for Optimal Power Flow Problem
}

\author{
Aboubakr Khelifi ${ }^{1 *}$, Bachir Bentouati ${ }^{1}$, Saliha Chettih $^{1}$, Ragab A. El-Sehiemy ${ }^{2}$ \\ ${ }^{1}$ Electrical Engineering Department, LMSF Laboratory, Amar Telidji University of Laghouat, Algeria \\ ${ }^{2}$ Electrical Engineering Department, Faculty of Engineering-Kafrelsheikh University, Egypt \\ ${ }^{1}$ Email: a.khelifi@lagh-univ.dz; b.bentouati@lagh-univ.dz; s.chettih@lagh-univ.dz. \\ ${ }^{2}$ Email: elsehiemy@eng.kfs.edu.eg;
}

Received: 24 October 2018; Accepted: 07 August 2019; Published: 08 September 2019

\begin{abstract}
Solving the Optimal power flow (OPF) problem is an urgent task for power system operators. It aims at finding the control variables' optimal scheduling subjected to several operational constraints to achieve certain economic, technical and environmental benefits. The OPF problem is mathematically expressed as a nonlinear optimization problem with contradictory objectives and subordinated to both constraints of equality and inequality. In this work, a new hybrid optimization technique, that integrates the merits of cuckoo search (CS) optimizer, is proposed to ameliorate the krill herd algorithm (KHA)'s poor efficiency. The proposed hybrid CS-KHA has been expanded for solving for single and multi-objective frameworks of the OPF problem through 11 case studies. The studied cases reflect various economic, technical and environmental requirements. These cases involve the following objectives: minimization of non- smooth generating fuel cost with valve-point loading effects, emission reduction, voltage stability enhancement and voltage profile improvement. The CS-KHA presents krill updating (KU) and krill abandoning (KA) operator derived from cuckoo search (CS) amid the procedure when the krill updating in order to extraordinarily improve its adequacy and dependability managing OPF problem. The viability of these improvements is examined on IEEE 30-bus, IEEE 57-bus and IEEE 118-bus test system. The experimental results prove the greatest ability of the proposed hybrid meta-heuristic CS-KHA compared to other famous methods.
\end{abstract}

Index Terms - Cuckoo search algorithm (CS); krill herd algorithm (KHA); optimal power flow (OPF); voltage stability (VS); valve-point effect; emission reduction.

\section{INTRODUCTION}

The problem of optimal power flow (OPF) is significated considerable attention in recent years and has based its position among the main tools for the operation and planning of recent power systems. OPF is a nonlinear programming problem. The major objective is to find the correct adjustment of its control variables that optimize specific objective functions/functions while sufficient the operational constraints of equality and inequality at specified loading settings and defined system parameters [1-3].

The OPF has been applied to regulate the production of real powers, generators terminal voltages, setting of transformer taps, shunt reactors/capacitors and other control variables to improve the power system requirements by minimizing the production fuel costs, reducing the network active power losses, enhance the voltage stability and voltage profile at load buses. The previous requirements are achieved while all operational requirements are preserved within the accepted operation limitations as The voltages of load bus, the reactive power products of the generator, the network's power flows and whole other state variables in the power system within their assure and operational bounds.

In its most popular formulation, the OPF is static, a non-convex, wide-ranging optimization problem with both discontinuous and continuous control variables. Even in operating cost functions' absence of non-convex generators, prohibited operating zones (POZ) of generating units and discontinuous control variables, the OPF problem is a non-convex because of the presence of non-linear alternating current power flow equality constraints. The existence of discontinuous control variables, like transformer tap positions, phase shifters, switchable shunt devices, added more difficulty the formulation and solution of the problem.

The methods were evolving to solve OPF problem can be categorized into two types conventional and advanced optimization techniques. The traditional optimization techniques were used derivatives and gradient operators. These techniques are usually not capable to find or determine the global optimal. Several mathematical suppositions like analytic, convex and differential objective functions must be made to simplicity the problem. Nevertheless, the OPF's problem is a problem of optimization non-convex and non-smooth objective function in general. As a result, it is significant to evolve optimization methods that are effective in dominating these disadvantages and to treat this hardness effectively. The computational materials' evolution in recent decades has motivated to the development of advanced optimization methods that were so-called meta-heuristics. 
These techniques can dominate many disadvantages of conventional techniques [4]. Several of these recent techniques have been applied to solve the OPF problem like: Simulated Annealing (SA) [5], Genetic Algorithm (GA) [6,7], Differential Evolution (DE) [8], Tabu Search (TS) [9], Imperialist Competitive Algorithm (ICA) [10], Particle Swarm Optimization (PSO) [11], adaptive real coded biogeography-based optimization (ARCBBO)[12], Biogeography Based Optimization (BBO) $[13,14]$, multiphase search algorithm [15], Gbest guided artificial bee colony algorithm(Gbest-ABC) [16], Gravitational Search Algorithm (GSA) [17] , Artificial Bee Colony (ABC) [18], Multi-objective Grey Wolf Optimizer (MOGWO)[19], black-hole-based optimization (BHBO) [20], Teaching Learning based Optimization (TLBO) [21], Sine-Cosine Optimization algorithm (SCOA) [22], Group Search Optimization (GSO) [23], hybrid algorithm of particle swarm optimizer with grey wolves(PSO-GWO) [24], quasi-oppositional teaching-learning based optimization [31]have been incorporated into it. Meanwhile, many state-of-the-art meta-heuristic techniques, like Improved Colliding Bodies Optimization (ICBO) [32], Moth Swarm Algorithm (MSA) [33], MothFlame Optimization (MFO) [34], cuckoo search [35], firefly algorithm [36] and Backtracking Search Optimization Algorithm (BSA) [37] Surveys of different meta-heuristics used to solve the problem of OPF are offered in[25] The applications of these methods on different size systems lead to competitive results and therefore were favorable and encouraging for more study in this trend. Furthermore, because of the objectives' contrast where various functions can be envisaged for modeling the OPF problem, of course not technique can be seen as the preferable in solving whole OPF problems. Hence, it is constantly needed to have a novel technique that can successfully solve several of the OPF problems.

Optimization is turning a area of request to analysts, particularly since a framework's the competence depends on obtaining an arrangement an order that can be acquired through suitable optimization technique. It is a method in order to discover the perfect solution next assessing the cost function that denotes the association among the system framework and its limitations. Presently, meta-heuristic algorithms are being formed in many regions for example crossbreeding, multi-objective type, binary type, preparing multi-layer perceptron and ways as Lévy flight, operator, and chaos theory. Most of these improvements happened because the deterministic and evolutionary components are used [23]. A perfect incorporation of global and local search has intensive local exploration and global exploration [25].

Krill herd method $(\mathrm{KH})$ first suggested by Gandomi and Alavi in 2012 [26] and because it performs well, many optimization strategies such as chaotic theory [27, 28, 36], Flower Pollination Algorithm (FPA) [29] and colonial competitive differential evolution (CCDE)[30] have been hybridized with the fundamental $\mathrm{KH}$ algorithm as mutation operator with the objective of further enhancing the performance of KHA. Furthermore, to make KHA perform in the most ideal way, a parametric study has been conducted through an array of standard benchmark functions [38].

Furthermore, KHA is a new population-build swarm computation [26] in view of the Lagrangian and revolutionary conduct of krill people in wildlife for utilization and investigation in a problem of optimization. $\mathrm{KH}$ computation occasionally is not able to must avoid local optimum [27] and [28].

Firstly, as portrayed here, a successful hybrid Meta heuristic cuckoo search krill herd (CS-KHA) technique in light of KHA and CS is initially suggested to accelerate convergence. In $\mathrm{CSKH}$, we use an essential KHA to select an encouraging solution set. Consequently, krill updating (KU) and krill abandoning (KA) operator started from CS algorithm are added to the method. The KU operator is to a decent encouraging arrangement; while KA operator is made use of further improving the investigation of the CS-KHA to substitute the worse krill's a small amount at the finale of every generation.

The performance of this approach is utilized to keep away from local optimum and obtain a worldwide ideal solution, in addition, minimal computational time to achieve the ideal solution, local minimum evasion, and quicker convergence, which produce them suitable for viable implementations for solving various constrained optimization problems. The purpose of this article is to develop an improved KHA called CS-KHA to solve OPF problem. So as to proven the evolution of the CS-KHA, its efficiencies are compared to CS, KHA and other wellknown optimization methods.

The rest of article is structured in the next form: The following segment outlines the formulation of the OPF problem; meanwhile, section 3 depicts the algebraic equation of CS-KHA. Section 4 shows the simulation's results and discussion. While the finally conclusion of this paper is in section 5 .

\section{Formulation OF OPTIMAL POWER FLOW (OPF)}

The problem of OPF aims at finding the control variables' optimal setting through minimizing /maximizing a predefined objective function while a collection of equality and inequality constraints satisfied. OPF considering the system's operating limit, hence it can be defined like a non-linear constrained optimization problem.

$$
\text { Minimize: } f(x, u)
$$

Subject to:

$$
\begin{aligned}
& h(x, u)=0 \\
& g(x, u) \leq 0
\end{aligned}
$$

Where, $u$ is the independent variable or control's vector, is the dependent variables or state's vector. Objective functions of OPF, $\mathrm{g}(x, u)$ : set of inequality constraints, $h(x, u)$ : set of equality constraints. 


\section{A. Control variables}

The vector of power network control variables is expressed as follows [37]:

$$
u=\left[P_{G_{2}} \cdots P_{G_{N G}}, V_{G_{1}} \cdots V_{G_{N G}}, Q_{C_{1}} \cdots Q_{C_{N C}}, T_{1} \cdots T_{N T}\right]
$$

Where, $P_{G_{i}}$ is the $i$-th active power bus generator. Chosen from bus 1 as swing bus is represented just and any one of the generator buses can be swing bus. $V_{G_{i}}$ is the voltage magnitude at $i$-th voltage controlled generator bus, $T j$ is the $j$-th branch transformer tap, $Q C k$ is the shunt compensation at $k$-th bus. $N G, N C$ and are the generators' number, transformers and shunt VAR compensators. Any value within its range can be assumed as a control variable. Practically, transformer taps are not constant. Be that as it may, the tap settings indicated are in p.u. and outright voltage's estimation is not represented Subsequently, for the aim of this study and to compare with previously described results, all control variables including tap settings are viewed constant for general cases of study.

\section{B. State (dependent) variables}

The power system's state variables can be expressed through vector $x$ as:

$$
x=\left[P_{G_{1}}, V_{L_{1}} \ldots V_{L_{N L}}, Q_{G_{1}} \ldots Q_{G_{N G}}, S_{l_{1}} \ldots S_{l_{n l}}\right]
$$

where, $P_{G_{1}}$ is the active power of generator at slack bus, $Q_{G_{i}}$ is the generator's reactive power linked to bus $i$, is the $p$-th load bus's bus voltage (PQ bus) and $q$-th line's line loading of is specified by. $N L$ and $n l$ are the load buses' number and lines of transmission respectively[40].

\section{Power System Constraints}

As aforesaid earlier, the problem of OPF presents both operational constraints on equality and inequality. These constraints are defined as follows:

\section{C.1. Equality constraints}

In OPF, the reactive and real power equilibrium equations are represented the system constraints of equality are formulated as for all system buses:

$$
\begin{gathered}
P_{G_{i}}-P_{D_{i}}-V_{i} \sum_{j=1}^{N B} V_{j}\left[G_{i j} \cos \left(\delta_{i j}\right)+B_{i j} \sin \left(\delta_{i j}\right)\right]=0 \\
Q_{G_{i}}-Q_{D_{i}}-V_{i} \sum_{j=1}^{N B} V_{j}\left[G_{i j} \sin \left(\delta_{i j}\right)+B_{i j} \cos \left(\delta_{i j}\right)\right]=0
\end{gathered}
$$

Where, $\delta_{i j}=\delta_{i}-\delta_{j}$ is the voltage angles among bus $i$ and bus $j, \mathrm{NB}$ is the buses' number, $Q_{D i}$ and $P_{D i}$ are reactive and real load demands. $G_{i j}$ is the transfer conductance and $\boldsymbol{B}_{i j}$ is the susceptance among bus $i$ and bus $j$, respectively.

\section{C.2. Inequality constraints}

The inequality's constraint in the OPF reflects the equipment's operating limit in the power system, and too reflects the limitation of the line and the load bus to ensure the safety of the system.

a) Generator constraints:

$$
\begin{gathered}
V_{G_{i}}^{\min } \leq V_{G_{i}} \leq V_{G_{i}}^{\max } \forall i \in N G \\
P_{G_{i}}^{\min } \leq P_{G_{i}} \leq P_{G_{i}}^{\max } \forall i \in N G \\
Q_{G_{i}}^{\min } \leq Q_{G_{i}} \leq Q_{G_{i}}^{\max } \forall i \in N G
\end{gathered}
$$

b) Transformer constraints:

$$
T_{j}^{\min } \leq T_{j} \leq T_{j}^{\max } \forall j \in N T
$$

c) Shunt compensator constraints:

$$
Q_{C_{k}}^{\min } \leq Q_{C_{k}} \leq Q_{C_{k}}^{\max } \forall k \in N C
$$

d) Security constraints:

$$
\begin{gathered}
V_{L_{p}}^{\min } \leq V_{L_{p}} \leq V_{L_{p}}^{\max } \forall p \in N L \\
S_{l_{q}} \leq S_{l_{q}}^{\max } \forall q \in n l
\end{gathered}
$$

The control variables in constraints of inequality are self-limiting. The technique of optimization chooses a viable value for every like variable within the determined scope. Efficient methods for dealing with constraints of inequality related to dependent or state variables.

\section{SugGested Hybrid TECHNIQUE}

\section{A. KH technique}

The KH technique is built on the natural inspiration of conduct krill individuals' imitation in the krill population. The KH technique is motivated by krill activities like [26] $1 /$ The movement of other krill individuals is induced; 2/Food search activity; 3/random scattering. The optimization technique has the ability to search for an uncertain search space.

- Lagrangian model is extended to an n-dimensional decision space:

$$
\frac{d X_{k}}{d t}=N_{k}+F_{k}+D_{k}
$$


Where $N_{k}$ the movement is stimulated by other members of the krill; $\boldsymbol{F}_{k}$ is the feeding movement and $D_{k}$ is the physical diffusion of the $k_{t h}$ krill.

The movement stimulated expresses the conservation of density through every individual. The matimatical formula reflects this conduct, which is worded as follows:

$$
\begin{gathered}
N_{k}^{\text {next }}=N^{\max } \alpha_{k}+\omega_{d} N_{k}^{\text {present }} \\
\alpha_{k}=\alpha_{k}^{\text {local }}+\alpha_{k}^{t \text { arget }}
\end{gathered}
$$

Wherein $N^{\max }$ is the highest stimulated velocity, $\omega_{d}$ indicates the inertia weight in $[0,1], N_{k}^{\text {Ancient }}$ is the preceding movement $\alpha_{k}^{\text {local }}$ and $\alpha_{k}^{t \arg e t}$ indicate the local effect of the neighbor, which is the best solution of the $k_{t h}$ individual. $\alpha_{k}^{t \arg e t}$ is formulated by the following equations:

$$
\begin{aligned}
\alpha_{k}^{t \text { arget }} & =C^{\text {best }} \hat{K}_{k, \text { best }} \hat{X}_{k, \text { best }} \\
C^{\text {best }} & =2\left(r_{1}+\frac{I}{I_{\max }}\right)
\end{aligned}
$$

where, $C^{\text {best }}$ is the krill individual's effective coefficient with the preferable fitness for the first $k_{t h}$ krill, $\hat{K}_{k \text {,worst }}$ and $\hat{K}_{k, \text { best }}$ are the worst and preferable krill's fitness value so far; is a random values' number among 0 and 1 . It is used to improve exploration, $I$ is the current iterations' number, and $I_{\max }$ is the iterations' maximum number.

Foraging activities/movements are mathematically calculated as follows:

The foraging action consists of two major parameters. Premier is the position of the food $F_{k}^{n e x t}$, followed by the preceding experiment $\beta_{k}$ around the position of the food.

$$
\begin{gathered}
F_{k}^{\text {next }}=V_{f} \beta_{k}+\omega_{f} F_{k}^{\text {previous }} \\
\beta_{k}=\beta_{k}^{\text {food }}+\beta_{k}^{\text {best }}
\end{gathered}
$$

Where, $V_{f}$ is the foraging speed, $\omega_{f}$ is the foraging motion's inertia weight in the field $[0,1], F_{k}^{\text {previous }}$ is the final foraging movement, $\beta_{k}^{\text {food }}$ is the food attractive and $\beta_{k}^{\text {best }}$ is the preferable fitness's effect of each krill. Depending on the foraging speed's measured values, take as $0.02\left(m s^{-1}\right)$.

$$
\begin{gathered}
D_{k}=D^{\max } \delta \\
D_{k}=D^{\max }\left(1-\frac{I}{I_{\max }}\right) \delta
\end{gathered}
$$

Wherein, $D^{\max }$ is the highest induction velocity, $\delta$ is the random direction vector $[0,1]$.

Lastly, the location of each krill is updated to:

$$
\begin{gathered}
X_{k}^{\text {next }}=X_{k}^{\text {current }}+\Delta x_{k}(t) \\
\Delta x(t)=N_{k}(t)+F_{k}(t)+D_{k}(t)
\end{gathered}
$$

Where, $\mathrm{t}$ is the krill's position.

\section{B. Cuckoo search}

Through optimizing the conduct of some cuckoo species, CS is suggested that is swarm intelligence's a type technique for optimization problems. In CS, Lévy flights are consolidated that decides the cuckoo's walking steps. For simplicity in portraying CS, Yang and Deb adopted some of the idealized rules. For instance, every cuckoo is just relating to one egg; the preferable nests would be preserved and not be obliterated; the possible host nest number is unchangeable, and an egg is recognized through the host bird with a possibility. In CS, every egg in a nest shows a solution. The CS is to take use of the recently created better solutions in place of a moderately poor solution. In this research, we just looked at every nest that merely had an egg. Thus, in this research, the difference between the nest egg and solution was not identified. The CS technique can make a good harmony between a local arbitrary walk and the irregular global exploratory walk using a switching parameter. The former one can be represented as

$$
X_{i}^{t+1}=X_{i}^{t}+\beta_{s} \otimes H\left(p_{a}-\varepsilon\right) \otimes\left(X_{j}^{t}-X_{k}^{t}\right)
$$

Where $X_{j}^{t}$ and $X_{k}^{t}$ are two various solutions choice at random, $\mathrm{H}(\mathrm{u})$ is function of a Heaviside , $\varepsilon$ is a number of random drawn from a regular distribution, and sis the step size. For the global random walk, it is combined with Lévy flights as follows:

$$
\begin{aligned}
& X_{i}{ }_{i+1}^{t+1}=X_{i}^{t}+\beta L(s, \lambda), L(s, \lambda)= \\
& \frac{\lambda \Gamma(\lambda) \sin \left(\frac{\pi \lambda}{2}\right)}{\pi} \frac{1}{s^{1}+\lambda},\left(s, s_{0} \succ 0\right)
\end{aligned}
$$

Here, $\beta \succ 0$ is the scaling factor of step size.

\section{Proposed Hybrid CS-KHA procedure}

To ameliorate the fundamental's the search capacity $\mathrm{KH}$ technique; genetic techniques are added to the method [26]. Numerical outcomes when contrast with 
other methods displays that KH II (only added crossover operator) performed the best.

In any case, $\mathrm{KH}$ can sometimes find it hard to come up with better solutions to several complicated problems. Consequently, in this article, a novel meta-heuristic technique by prompting $\mathrm{KU}$ operator and KA operator into $\mathrm{KH}$ to form a recent hybrid method, named CS-KHA is used to manage an OPF problem. The introduced KU/KA operators are roused by the authoritative CS algorithm. As such, in this paper, the property of cuckoo used in CS is supplemented to the krill to create excellent krill's a sort that can play out the KU/KA operator. The contrast amongst $\mathrm{CSKH}$ and $\mathrm{KH}$ is that the $\mathrm{KU}$ operator as a local search tool is used to adjust the new solution for every krill rather than rand walks used as KH's part (whereas in KH II, genetic generation techniques are employed). While KA operator is used to enhance further the exploration the method's ability by replacing some nests randomly thereby constructing new solutions. By the blending of $\mathrm{CS}$ and $\mathrm{KH}, \mathrm{CSKH}$ can investigate the new search space with standard $\mathrm{KH}$ technique and KA operator and exploit the population information by $\mathrm{KU}$ operator. The main step of KU/KA operators used in CSKH method is presented by Algorithms 1 and 2, respectively.

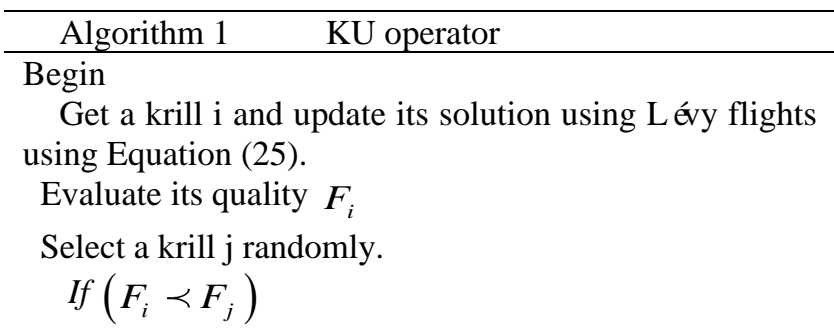

Replace $\mathrm{j}$ with the novel solution and take the novel solution as $X_{i+1}$ Else

Update the position of krill using equation (22) as $X_{i+1}$ end if

End.

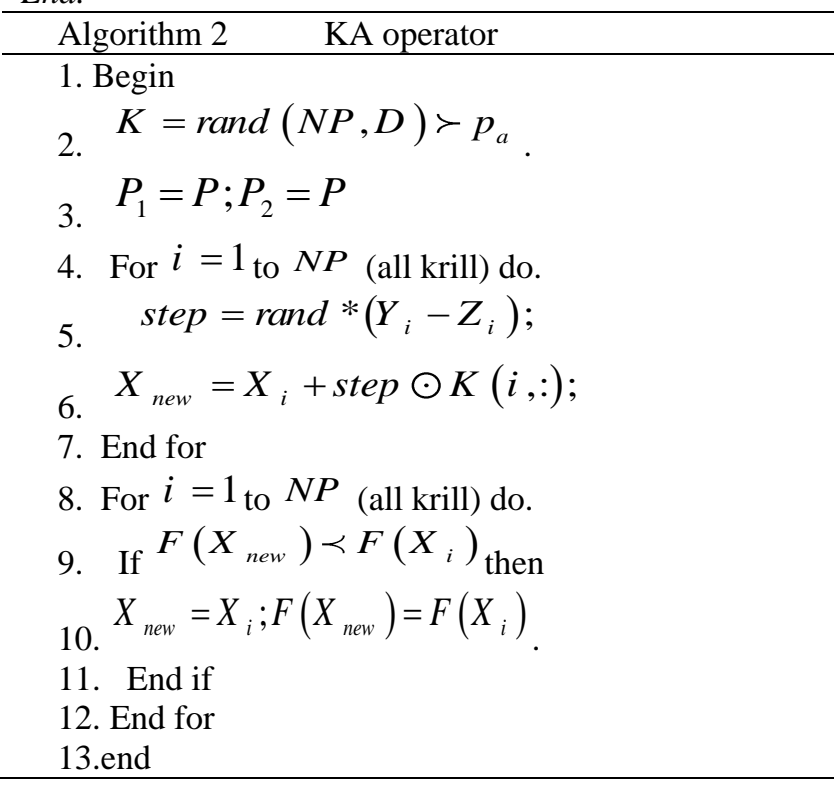

Firstly in the proposed method, standard KHA uses three movements to look for the best solutions and engage these movements to lead the candidate solutions for the following generation. In this, KU operator is then employed to carry out local search intensively to achieve better solutions. This operator can since it abuses the search space by Lévy flight. Towards the end of each generation, the KA operator is employed to additionally ameliorate the CS-KHA's the exploration by replacing the worse krill's a fraction (pa) .Along these lines, this component used in CS-KHA can completely extend the strong the KHA's exploration and gain overcome the absence of the KHA's weak exploitation . Above all, this technique can additional unwind the inconsistency among exploration and exploitation effectively. Furthermore, another basic change is the presentation of elitism scheme into the CSKH. Likewise, with other population-based methodologies, we employ a further focused elitism technique to hold the preferable solutions for the population. That elitism system forbids the preferable krill from existence demolished through three movements and KU/KA operator. By joining previously mentioned $\mathrm{KU} / \mathrm{KA}$ operator and concentrated elitism design into unique $\mathrm{KH}$ technique to form a new CSKH algorithm (see Algorithm 3).

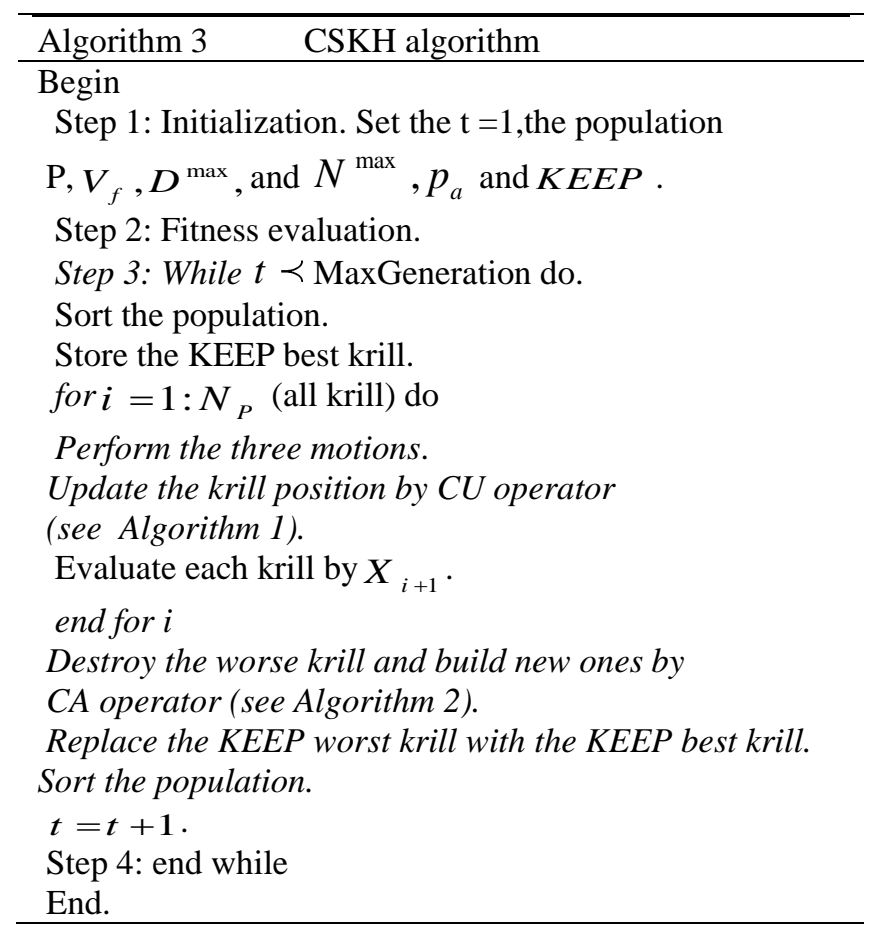

\section{OBJeCtive FUnCTIONS AND STUdiEd CASES}

A few contextual investigations with unique and multiobjective have been made for networks IEEE 30-bus, IEEE 57-bus and IEEE 118-bus test systems. The essential characteristics of this networks exam system are given in [33].

\section{A. IEEE 30 Bus system results}




\section{A.1.Studied Cases}

A total of 8 studies of cases were implementing in the first exam system (IEEE 30-bus exam system). The first two cases studies reduced OPF's single objective function. The rest is multi-objective optimization, which translates into a single target with a weighting factor, as in numerous past studies and recreated here. The definitions of the studied cases are expressed as follows:

\section{Case 1: fuel cost's minimization}

This is the fundamental OPF's objective function in all studies. The relationship among fuel cost $(\$ / h)$ and power generation Power (MW) is generally offered by two relationships, so the target function to be is reported as:

$$
f(x, u)=\sum_{i=1}^{N G} a_{i}+b_{i} P_{G_{i}}+c_{i} P_{G_{i}}^{2}
$$

Where $a_{i}, b_{i}, c_{i}$ are the $i$-th generator's cost coefficients generating produce power. IEEE 30-bus system generators' cost coefficients can be seen in [39].

Case 2: fuel cost's minimization taking into account valve point effect

The impact of the valve point should be taken into account for further practical and exact fuel cost function's modeling. The generating units with multi-valve steam turbines display a more prominent variety in the fuel-cost functions [32]. The valve loading multi-valve steam turbines' impact is modeled as function of sinusoidal, which's the absolute value is added to the fundamental cost function. The steam plant's actual cost curve function becomes non-continuous. The aim of reducing fuel cost of generating with valve-point effect is presented by [40]:

$$
f(x, u)=\sum_{i=1}^{N G}\left(a_{i}+b_{i} P_{G_{i}}+c_{i} P_{G_{i}}^{2}\right)+\left|d_{i} \times \sin \left(e_{i} \times\left(P_{G_{i}}^{\min }-P_{G_{i}}\right)\right)\right|(28)
$$

Where, $d_{i}$ and $e_{i}$ are the coefficients that show the valve-point loading effect. The factors applied for calculations are given in [37].

\section{Case 3: Fuel cost's minimization and voltage stability enhancement}

Voltage dependability issues are accepting developing consideration in power systems as network breakdown have been experienced in last because of instability of voltage. Under normal condition and in the wakw of being subjected to unsettling influence, the power system's steadiness is portrayed through its capacity to keep up whole bus voltages in suitable boundaries. A system goes into voltage instability's a condition when an unsettling influence, augmentation in load demand or variation in system term causes a dynamic and wild abatement in voltage[14]. Systems with long lines of transmission and overwhelming loading are further inclined to the problem of voltage instability. In power system, a system's enhancing voltage stability is a vital part. Each bus's $L$-index fills in as perfect power system stability's marker [42]. The index's value can be between 0 and 1 , where 0 existence the no load case whereas 1 is the voltage collapse. If a power system has NL load (PQ) buses' number and NG generator (PV) buses' number , L-index Lj's value of bus $j$ is can be explained as:

$$
L_{j}=\left|1-\sum_{i=1}^{N G} F_{j i} \frac{V_{i}}{V_{j}}\right|, \text { where } j=1,2, \ldots, N L
$$

and

$$
F_{j i}=-\left[Y_{L L}\right]^{-1}\left[Y_{L G}\right]
$$

Where, $Y_{L L}$ and $Y_{L G}$ sub-matrices and are gotten from YBUS system matrix next separating load (PQ) buses and generator (PV) buses as shown in (29).

$$
\begin{gathered}
{\left[\begin{array}{c}
I_{L} \\
I_{G}
\end{array}\right]=\left[\begin{array}{ll}
Y_{L L} & Y_{L G} \\
Y_{G L} & Y_{G L}
\end{array}\right]\left[\begin{array}{c}
V_{L} \\
V_{G}
\end{array}\right]} \\
L_{\max }=\max \left(L_{j}\right) j=1,2 \ldots \ldots, N L
\end{gathered}
$$

The indicator $L_{\max }$ varies among 0 and 1 where the minimal the indicator, the further the system stable. Thus, enhancing voltage stability can be obtained by the reducing of $L_{\max }$. Hence, the objective function can be formulated as:

$$
f(x, u)=\left(\sum_{i=1}^{N G} a_{i}+b_{i} P_{G_{i}}+c_{i} P_{G_{i}}^{2}\right)+\lambda_{L} \times L_{\max }
$$

Where, $L_{\max }$ is chosen weight factor's value $\lambda_{L}$ is 100 .

\section{Case 4: Fuel cost's minimization and emission}

Electrical power's generation from traditional energy's sources releases dangerous gases for the environment. The nitrogen oxides (NOx) and sulfur oxides (SOx)'s amount and emission in tones per $\mathrm{hr}(\mathrm{t} / \mathrm{h})$ is higher with augmented in generated power (in p.u. MW) next the relationship presented in Eq. (33).

$$
\text { Emission }=\sum_{i=1}^{N B}\left[\left(\alpha_{i}+\beta_{i} P_{G_{i}}+\gamma_{i} P_{G_{i}}^{2}\right) \times 0.001+\omega_{i} e^{\left(\mu_{i} P_{G_{i}}\right)}\right]
$$

Where, $\alpha_{i}, \beta_{i}, \gamma_{i}, \omega_{i}$ and $\mu_{i}$ are all coefficients of emission provided in [41].

Therefore, the objective function of this case is given by:

$$
f(x, u)=\left(\sum_{i=1}^{N G} a_{i}+b_{i} P_{G_{i}}+c_{i} P_{G_{i}}^{2}\right)+\lambda_{E} \times \text { Emission }
$$

The weight factors are chosen as $=100$ in this case 


\section{Case 5: fuel cost's minimization and voltage deviation}

Deviation of voltage is voltage quality's a measure in the network. The deviation's index is too vital from the security part. The indicator is expressed as cumulative voltages deviation of whole load buses in the network from nominal unity's value. Mathematically it is formulated as:

$$
V D=\left(\sum_{p=1}^{N L}\left|V_{L_{p}}-1\right|\right)
$$

The combining fuel cost's objective function and deviation of voltage is:

$$
f(x, u)=\left(\sum_{i=1}^{N G} a_{i}+b_{i} P_{G_{i}}+c_{i} P_{G_{i}}^{2}\right)+\lambda_{V D} \times V D
$$

Where, factor of weight is give a value of 100 as in $[32,33]$.

\section{Case 6: Fuel cost minimization and active power loss}

The power loss in system of transmission is certain because the lines have latent resistance. The active power loss to be reduced is formulated as:

$$
P_{\text {loss }}=\sum_{i=1}^{n l} \sum_{j=1, j \neq i}^{n l} G_{i j}\left[V_{i}^{2}+V_{j}^{2}-2 V_{i} V_{j} \cos \left(\delta_{i j}\right)\right]
$$

A multi-objective case that aims at reducing fuel cost and active power loss simultaneously is transformed into single objective as:

$$
f(x, u)=\sum_{i=1}^{N G} a_{i}+b_{i} P_{G_{i}}+c_{i} P_{G_{i}}^{2}+\lambda_{p} \times P_{\text {loss }}
$$

Where, $P_{\text {loss }}$ is the active power loss and factor's value $\lambda_{p}$ is selection as 40 .

Case 7: Fuel cost's minimization and voltage stability's enhancement

The objective function's formulation, comprising of both fuel cost taking into account the valve-point effect and voltage stability, this case's the objective function can be expressed as:

$$
\begin{aligned}
& f(x, u)=\sum_{i=1}^{N G}\left(a_{i}+b_{i} P_{i}+c_{i} P_{i}^{2}\right)+ \\
& \left|d_{i} \times\left(e_{i} \times \sin \left(P_{g i}^{\min }-P_{g i}\right)\right)\right|+\lambda_{L} \times L_{\max }
\end{aligned}
$$

The choice weight factor $\lambda L$ is too 100 .

Case 8: fuel cost's minimization, emission, voltage deviation and losses
Four objectives are put together for this case study. Fuel cost, emission, voltage deviation and active power loss in the network are whole reduced together. The objective function is presented by:

$$
\begin{aligned}
& f(x, u)=\left(\sum_{i=1}^{N G} a_{i}+b_{i} P_{i}+c_{i} P_{i}^{2}\right)+\lambda_{E} \times \\
& \text { Emission }+\lambda_{V D} \times V D+\lambda_{p} \times P_{\text {loss }}
\end{aligned}
$$

The weight factors are choice as in [33] with $\lambda_{E}=19$, $\lambda_{V D}=21$ and $\lambda_{p}=22$ to balance between the objectives.

\section{RESULTS AND DISCUSSION}

For optimizing's case 1 essential fuel cost, CS-KHA algorithms can produce to fuel costs of $799.0595 \$ / \mathrm{h}$ which satisfies all the system constraints, complying to the vital constraints of inequality on generator reactive power, load bus voltage and line capacity . Amongst whole the constraints of inequality, constraint on load bus voltage was discovered to be vital as the load buses' operating voltages are sometimes establish to be close the boundaries. Using the 3-methods (CS, KHA and CSKHA), recent studies recorded better results when compared with present study are presented in table 2 . The valve-point effect is studied for case 2 to achieve at a rise in cost than in case 1 with conclusive value of $830.0981 \$ / \mathrm{h}$, get by CS-KHA. In a nutshell, in spite of the variation in efficiency is seen between three methods, produce one or more technique's outcome used in our work are better than most of the results revealed in past literatures on the problem of OPF are presented in table 2.

Case 3 to case 8 are for OPF with multi-objective for 30-bus system. In these case studies, the joined objective function's fitness is the significant factor in ranking the different optimization techniques' outcome out. For a significant comparison, other techniques' fitness value is calculated and provided here employing the different objective functions' are weight factor. In multi-objective cases, an adjustment in weight factor e.g. elevated weight factor on fuel cost in case 3 the best values of both fuel cost and the system load buses' Lmax, CS-KHA gives preferable produce of 799.5625 and 0.1251 respectively, superior to the other comparable algorithms as appears in the table 2. Two objectives of cost and emission are concurrently reduced in case 4 . Along with the fitness value, CS-KHA is at the cost and emission's least values in compared with in compared with other techniques presented in table 4.

Minimizing cost and voltage deviation (VD)'s in case 5, is achieved by CS-KHA which is the least among all other comparable techniques as appear in table 4.

In case 6 will reduce the cost and power loss. Table 3 shows' quick review that any these techniques' one or more CS, KHA and CS-KHA can give the preferable fitness values in whole the cases. Despite the fact that the preferable fitness is described by CS-KHA in case 6, a 
transitional value fuel cost, the forming objectives' one, is accomplished. The active power loss's other goal is the minimum when compared with other methods as appears in table 4.

\section{Convergence curve}

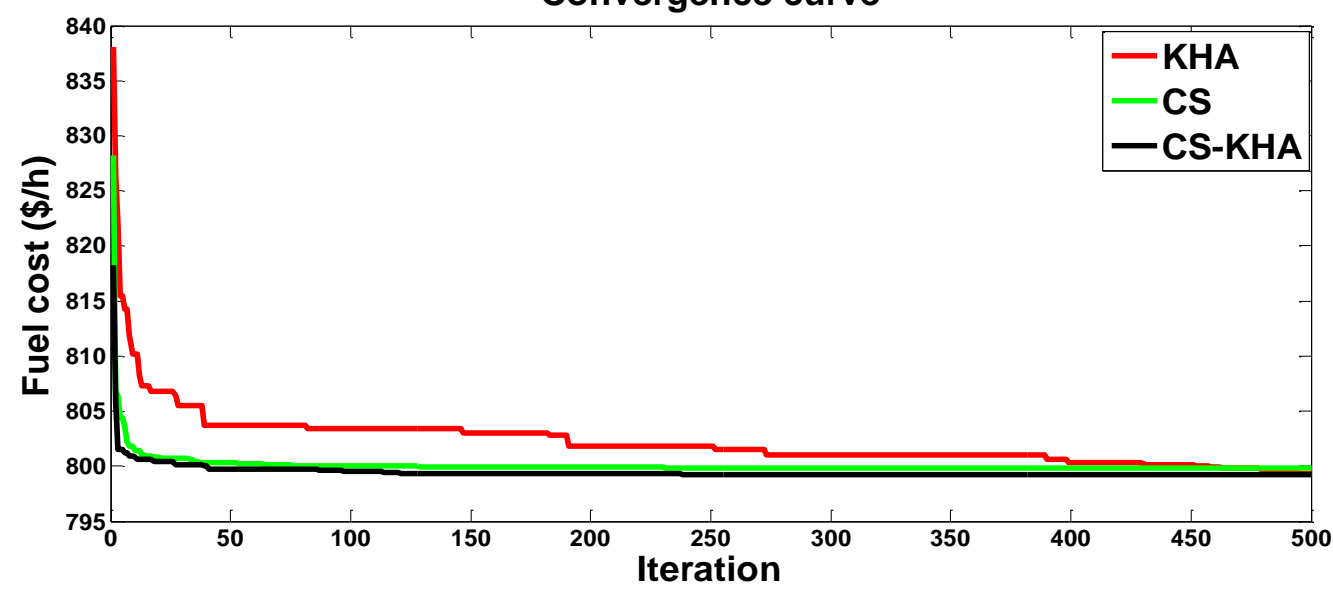

Fig.1. Convergent curves of Case 1

Table 1. The control variables' optimal settings for Cases 1-3.

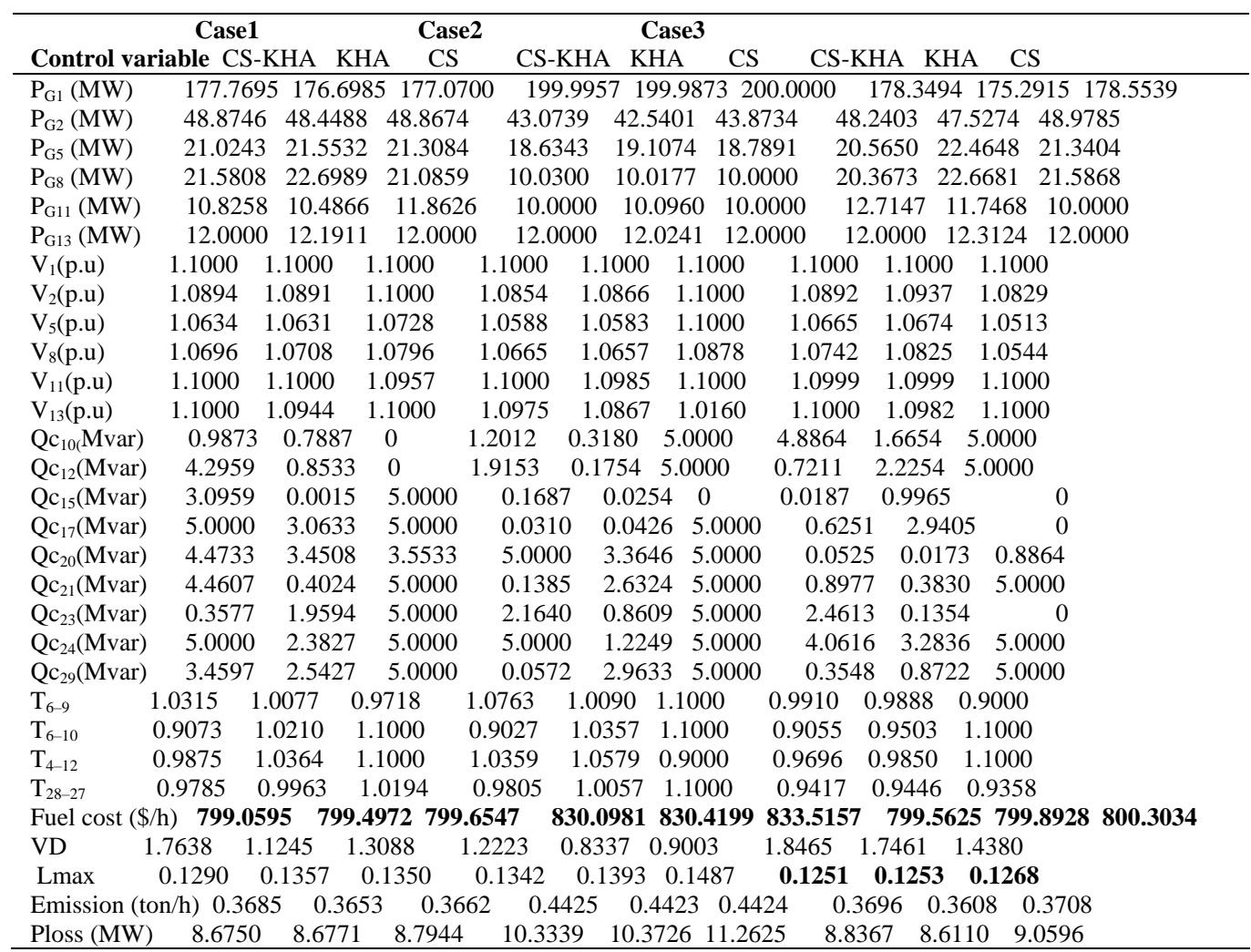

Table 2. the results obtained are compared for Cases 1-3

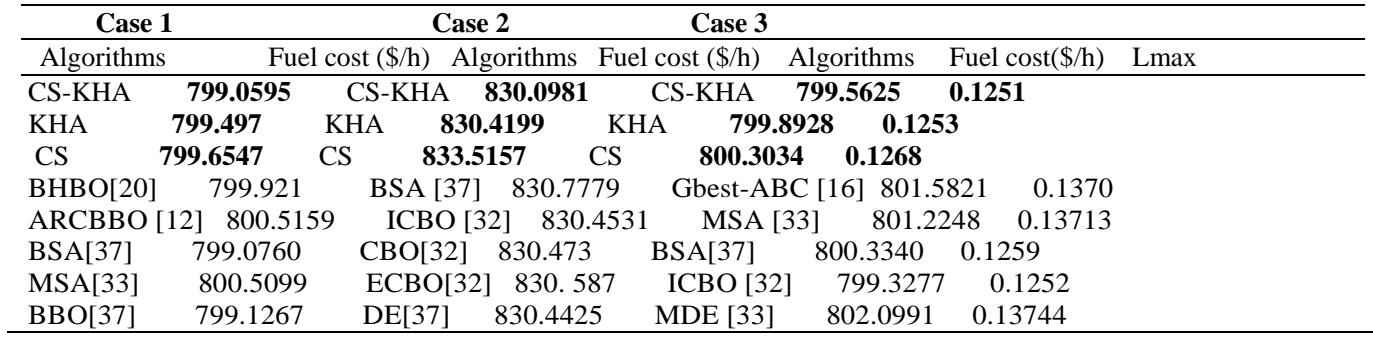


Table 3. the control variables' optimal settings for Cases 4-6.

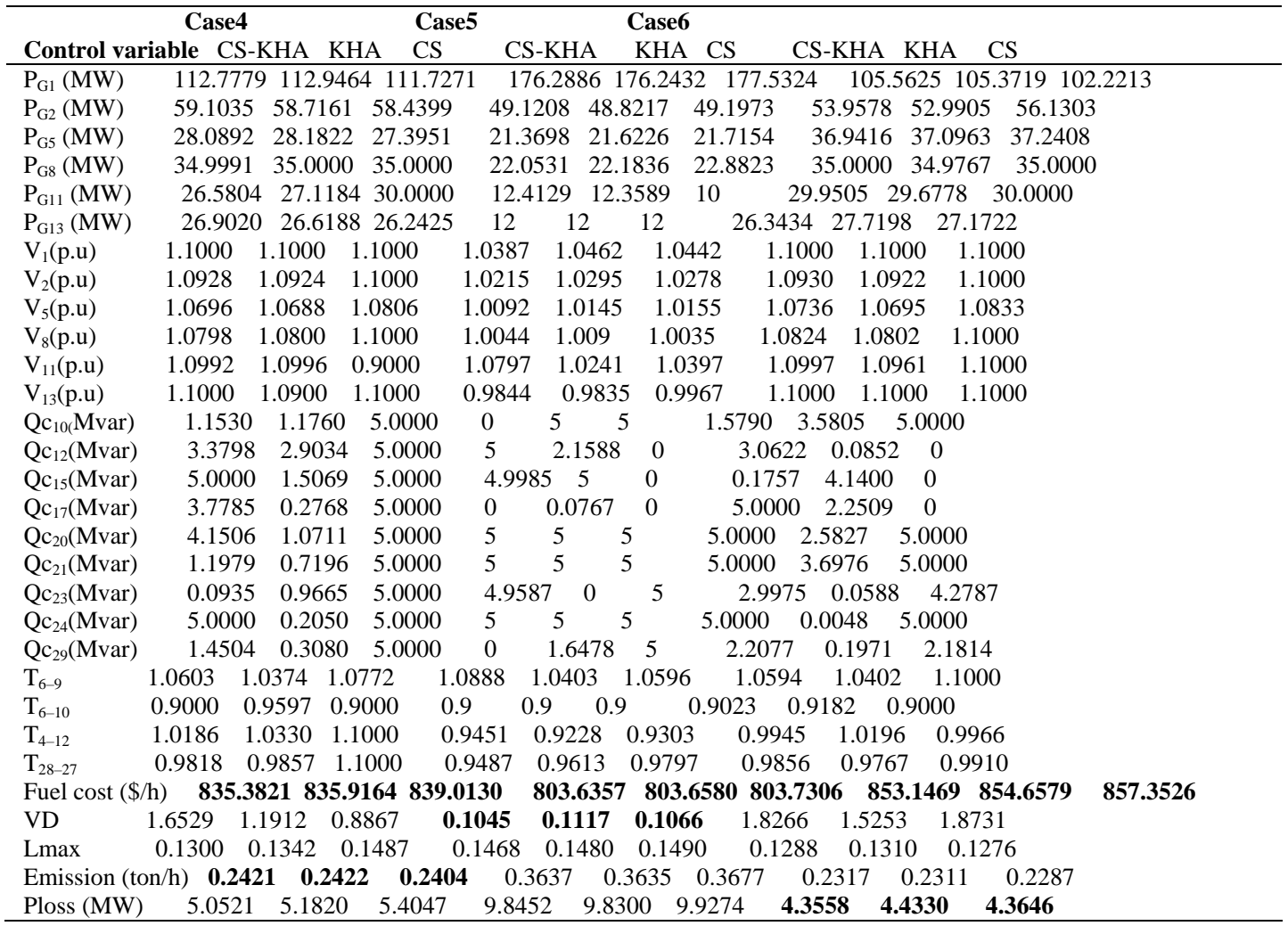

Table 4. The results obtained are compared for Cases 4-6.

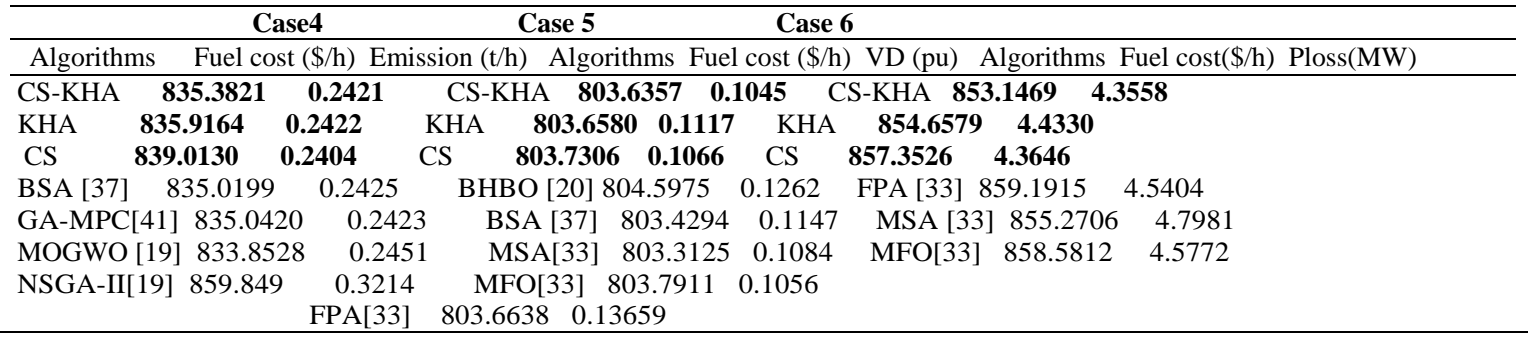

Table 5. The control variables' optimal settings for Cases 7 and 8 .

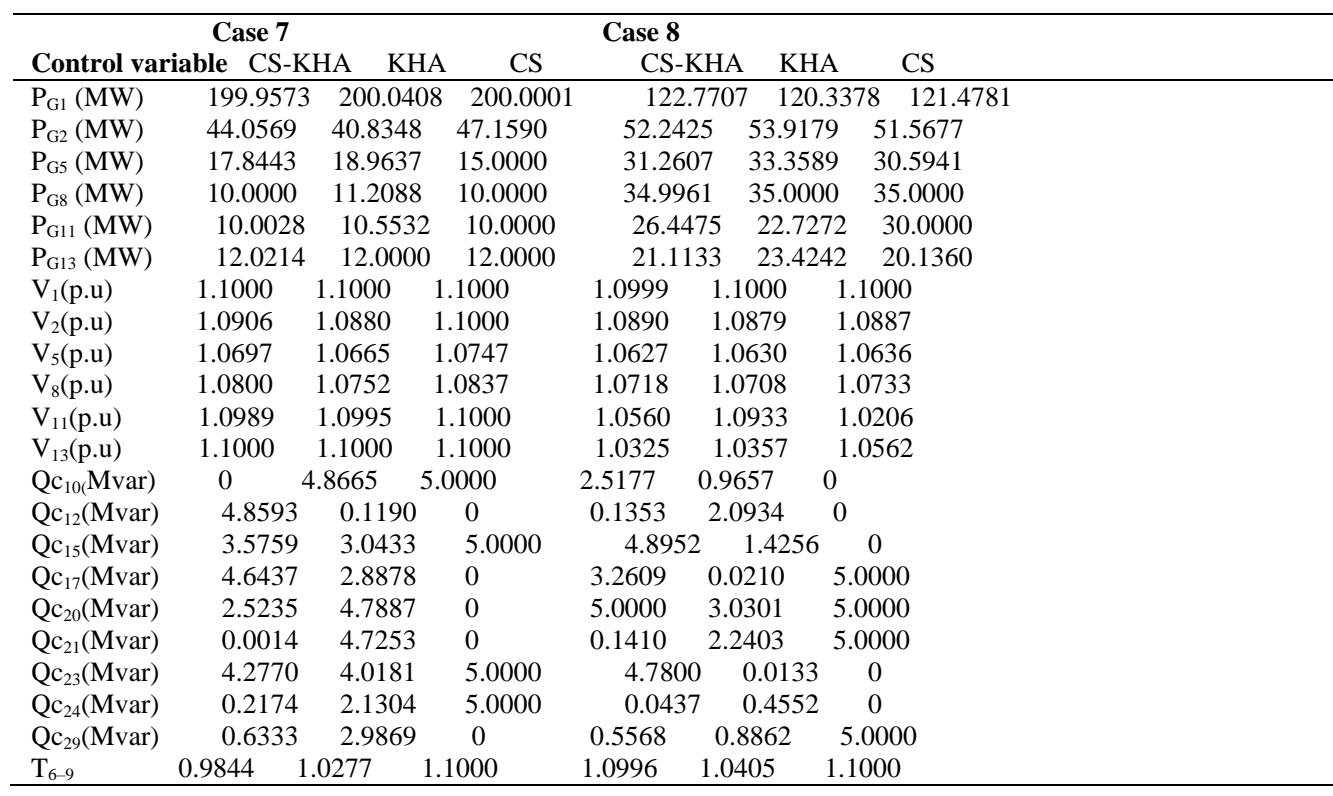




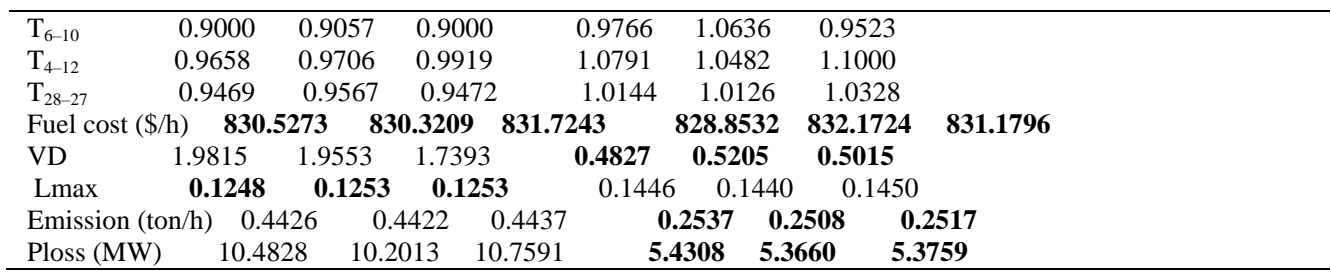

Table 6. The results obtained are compared for Cases 7 and 8.

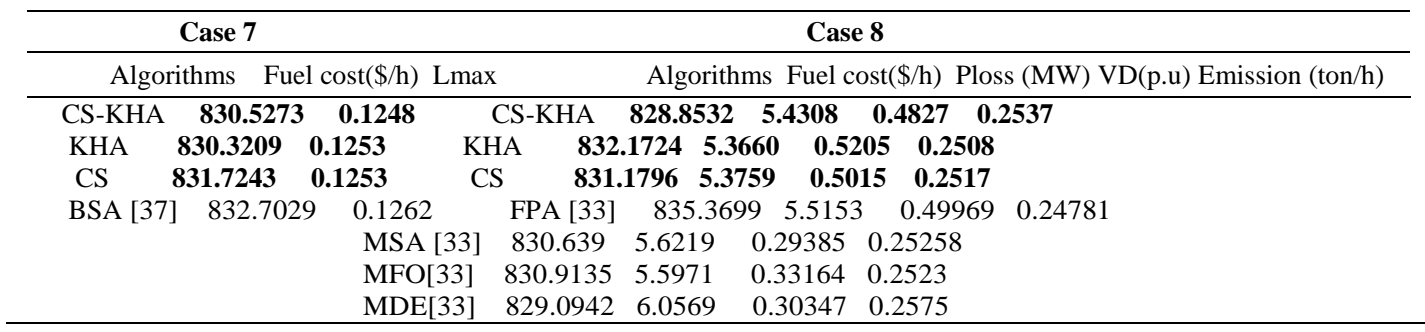

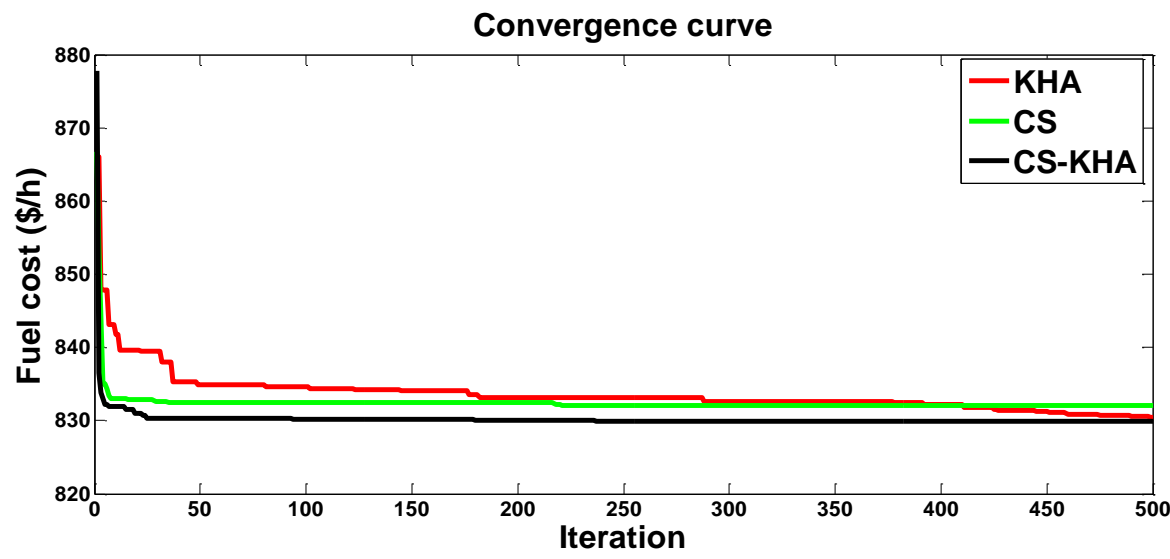

Fig.2. Convergent curves of Case 2

Important amelioration in fuel cost seen (through CSKHA) in case 7's for multi-objective optimization where both cost considering the valve-point effect and $L$-max are minimized. Preferable to the other comparable algorithms as appears in table 6.

Cost, real power loss, emission and voltage deviation concurrently reduced four objectives are in case 8. Along with the fitness value, CS-KHA is at the cost and loss's least values in contrast with MSA [33] and FPA [33], as shown in Table 6. Graphical comparison the convergence of three proposed techniques for Case 1 and Case 2 of the objective functions related to the fuel cost is shown in Figures 1 and 2 respectively. The convergence speeds are Not distinctly various between the techniques. Be that as it may, fast and surprising convergence is seen for both KHA and CS-KHA during the search process's first phase. KHA converges to the ideal solution more consistently. Two-objective cases' convergences are given in Fig.3. (3.a and 3.b), Fig. 4. and Fig. 5. (5.a and 5.b). For clarity, only one technique's convergence achieving optimal fitness value is shown in the graph.

\section{Comparison among CS, KHA and CS- KHA}

Table 7. Shows the statistical summary of 30 runs using three proposed algorithm as the fundamental search technique for each study carried out. The columns denote the best, worst, average and standard deviation values of the objective function in every case. It is clear that no single technique is capable to issue the best mean values in whole the cases. CS-KHA is found to be superior to KHA and CS in all cases for 30-bus and 57-bus system.

\section{A. Results of IEEE 57-bus test system}

So as to exam the usability of the suggested CS-KHA technique, a greater test system is take into account in this article, which is the IEEE 57-bus test system. 57-bus system's general system data are given in [43].

\section{CASE 9: fuel cost minimization}

The goal of this case is to reduce the total generating fuel cost. Hence, this case's the objective function is presented by (27). The CS-KHA is implementation so as to get the optimal settings for this case and the gained results are presented in Table 8 . In this case minimizing the fuel cost's fundamental objective produce to a value of $41660.2273 \$ / \mathrm{h}$ by CS-KHA, the most minimal when compared with other recent studies' substantial results as seen in Table 9.

\section{CASE 10: Fuel cost minimization and voltage deviation}

The purpose of the objective function is to reduce simultaneously both fuel cost and voltage deviation. The transformed single objective function next equation (36) 
with weight factor $\lambda_{V D}$ is chosen as 100 . The results of such optimization using the suggested CS-KHA technique are given in Table 8 . This table shows that the VD has been decrease from (1.5991 p.u.) to (0.6940 p.u.) compared with CASE 9. Hence, the cost has slightly augmented from $(41660.2273 \$ / \mathrm{h})$ to $(41712 \$ / \mathrm{h})$ compared with CASE 9.

\section{B. Results of IEEE 118-bus test system:}

\section{CASE 11: Fuel cost minimization}

To prove performance of the suggested hybrid CSKHA, the large-scale IEEE 118-bus system is deliberated for study goal, the essential characteristics are presented in [43]. In general, the efficiency of the proposed algorithm is excellent for variables' higher number in constrained optimization problems. Therefore, CS-KHA method is utilized to the system to decrease fuel cost. Hence, this case's objective function is presented by (27). The CS-KHA is implemented so as to get the optimal settings for this case and the gained results are presented in Table10. In this case, minimizing the fuel cost's fundamental objective produce to a value of $135260.45 \$ / \mathrm{h}$ by CS-KHA, the most minimal when compared with other recent studies' substantial results as seen in Table 11.

\section{CONCLUSION}

In present study, a new Meta hybrid heuristic CSKH technique has been suggested to solve the problem of OPF. By merging the merits KU/KA operator of CS technique with the $\mathrm{KH}$ technique. Hence, the $\mathrm{KH}$ is improved and the $\mathrm{CSKH}$ algorithm is evaluated numerically.
The detailed expression of a new variant of $\mathrm{KH}$ algorithm is given, and the $\mathrm{KU}$ operator is adjusted dynamically in $\mathrm{KU}$ process. In the proposed hybrid CSKHA, a greedy option was used, often surpassing the standard CS and KH. Moreover, so as to more ameliorate the CSKH's exploration, each generation of end KA operators will be a small number of poor krill thrown away, and replaced by new randomly generated krill. The problem of OPF has been expressed as a constrained optimization problem where many objective functions have been taking into account to decrease the fuel cost, to enhance the voltage stability and to improve the voltage profile. However, non-smooth piece-wise quadratic cost objective function has been deliberated. The feasibility of the suggested CS-KHA technique for solving problems of OPF is confirm by apply three standard test power systems. The results of the simulation prove the success and robustness of the suggested method to solve problem of OPF in small and large test systems. In addition, the suggested methods in this study achieve significantly better than several other equivalent optimization techniques in obtaining solutions of OPF. Decrease in hourly operation cost has been based almost in whole the cases studied in the context of this literature. In order to add more complex objectives function when solving OPF problems, no method is the best way to solve all OPF problems. Therefore, there is always a require for a new method, capable of successfully solving as many OPF problems as possible. However, increased capability is often achieved by hybridizing method and deterministic optimization techniques. In the future, different settings of optimization techniques used in this article are chosen by trial and error to improve convergence characteristics and these settings can be optimized for improved effectiveness. Various types of sources energy, like solar cells, wind turbines can be involved in solving OPF problems.

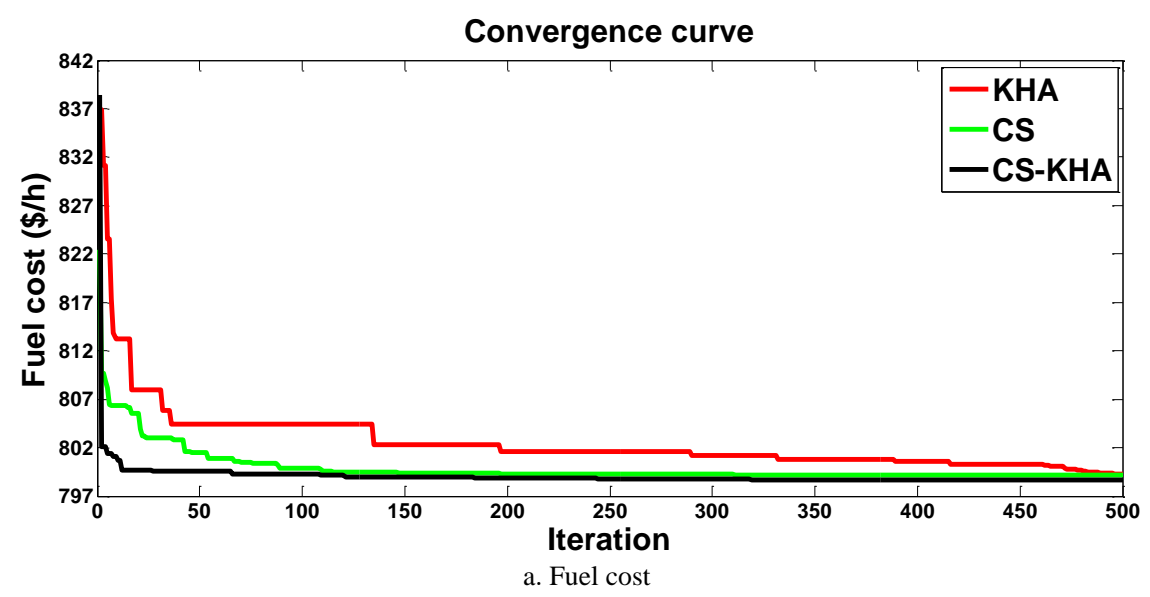




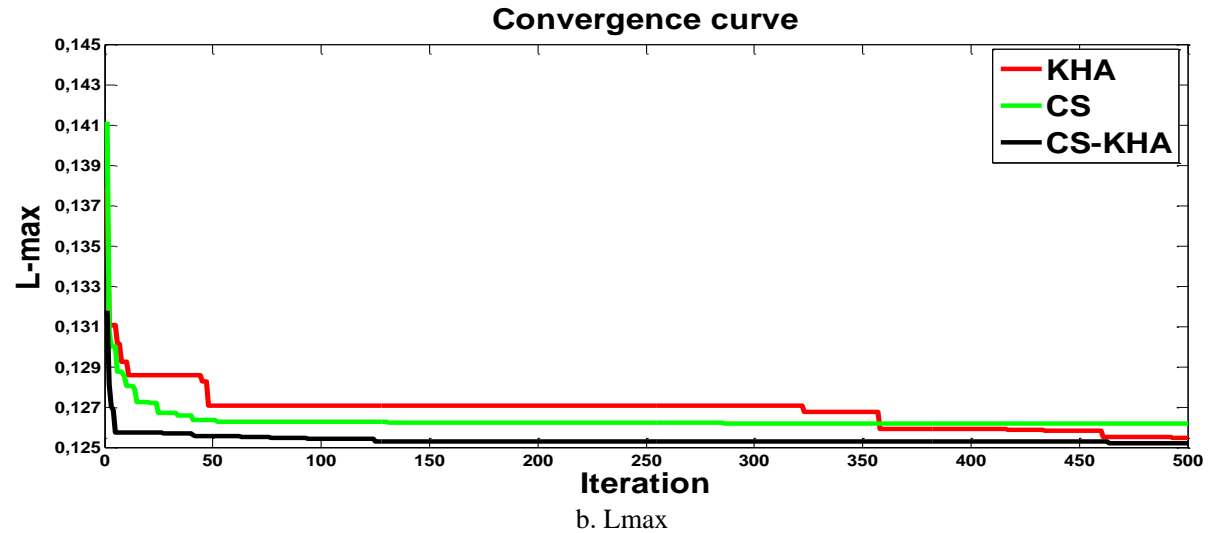

Fig.3. Convergent curves of Cas3 (bi-objectives)

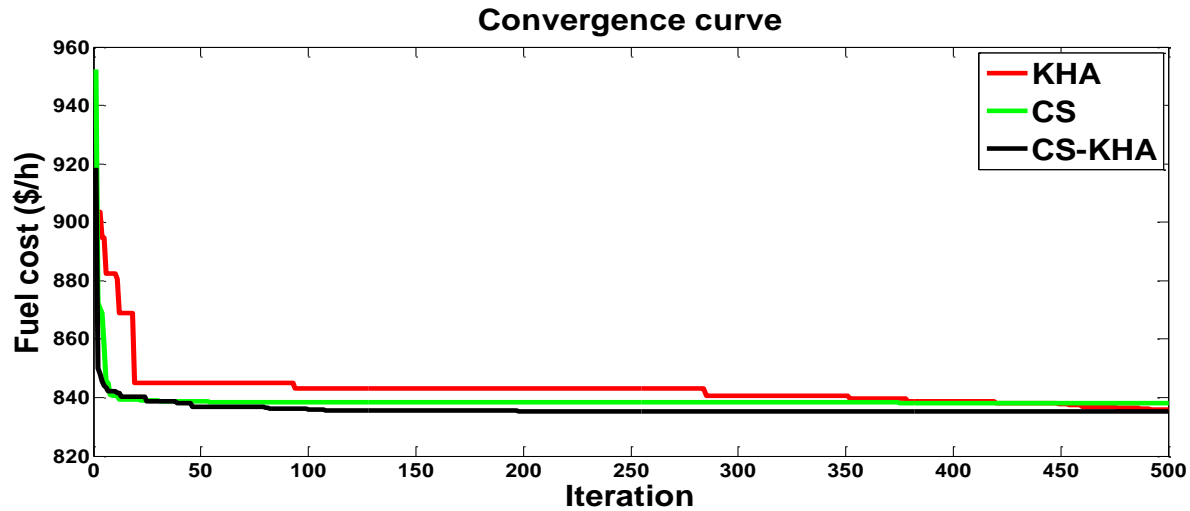

Fig.4. Convergent curves of Case 4

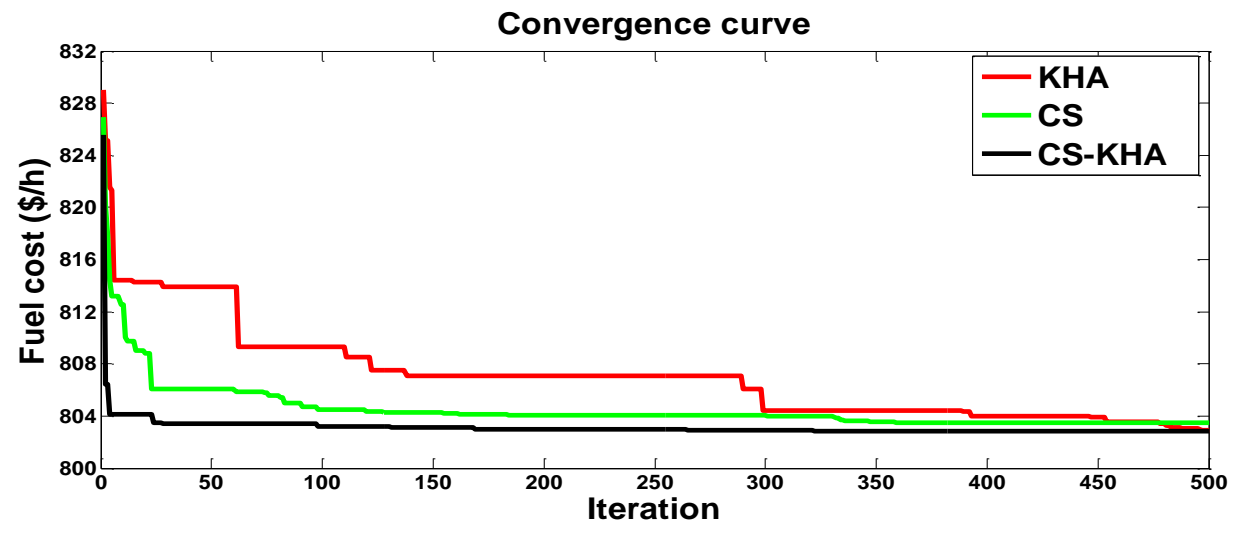

a. Fuel cost

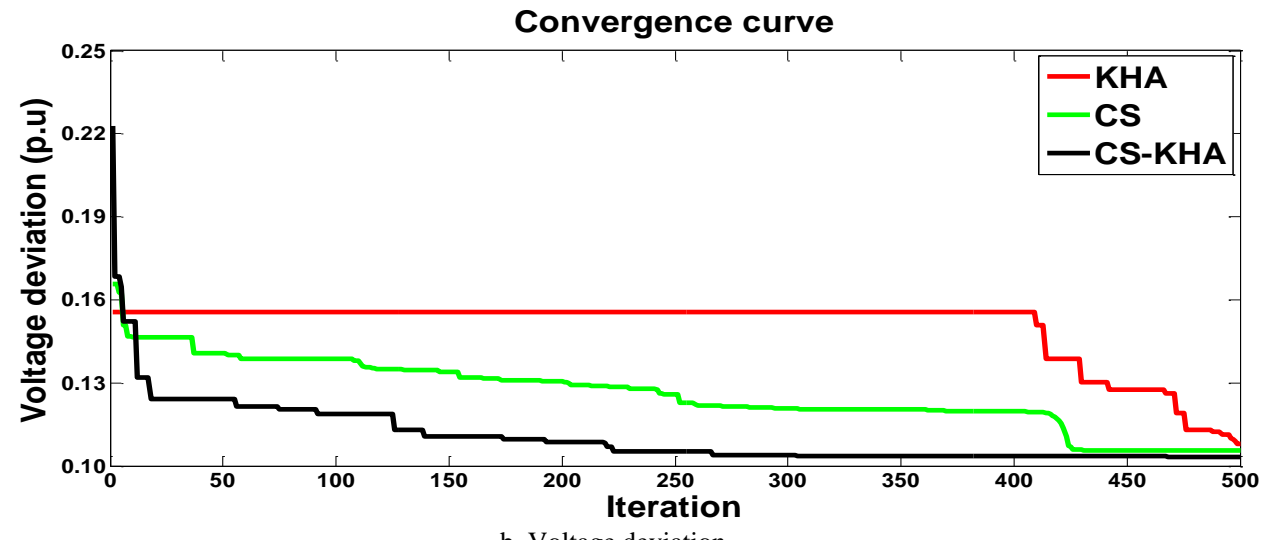

b. Voltage deviation

Fig.5. Convergent curves of the objectives of Case 5 
Table 7. Summary of statistical indices of the CS-KHA with CS, KHA for Cases 1-10

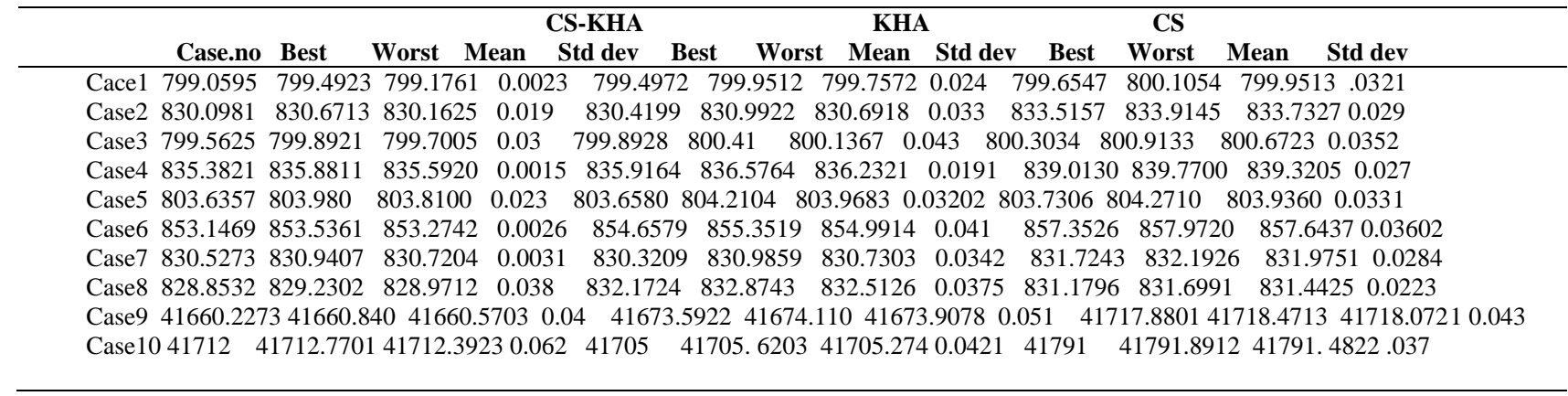

Table 8. The control variables' optimal settings for Cases 9 and 10 .

\begin{tabular}{|c|c|c|c|c|c|c|}
\hline \multirow{2}{*}{ Control variable } & \multicolumn{3}{|c|}{ Case 9} & \multicolumn{3}{|c|}{ Case 10} \\
\hline & le CS-KHA & KHA & $\mathrm{CS}$ & CS-KHA & KHA & $\mathrm{CS}$ \\
\hline $\mathrm{P}_{\mathrm{G} 1}(\mathrm{MW})$ & 143.4297 & 145.0358 & 140.9221 & 140.6795 & 141.9955 & 146.9150 \\
\hline $\mathrm{P}_{\mathrm{G} 2}(\mathrm{MW})$ & 87.0645 & 98.1294 & 77.7157 & 94.9802 & 92.1514 & 100.0000 \\
\hline $\mathrm{P}_{\mathrm{G} 3}(\mathrm{MW})$ & 45.1917 & 47.2053 & 40.0000 & 47.1461 & 45.7668 & 40.0000 \\
\hline $\mathrm{P}_{\mathrm{G} 6}(\mathrm{MW})$ & 67.0035 & 54.0795 & 100.0000 & 66.5315 & 78.1945 & 100.0000 \\
\hline $\mathrm{P}_{\mathrm{G} 8}(\mathrm{MW})$ & 459.5789 & 472.6903 & 453.4311 & 460.6278 & $8 \quad 460.5117$ & 478.9845 \\
\hline $\mathrm{P}_{\mathrm{G} 9}(\mathrm{MW})$ & 99.7951 & 81.2897 & 100.0000 & 94.4812 & 89.2280 & 30.0000 \\
\hline $\mathrm{P}_{\mathrm{G} 12}(\mathrm{MW})$ & 363.2292 & 367.0996 & 354.6953 & 362.1398 & $8 \quad 358.8398$ & 371.7001 \\
\hline $\mathrm{V}_{1}(\mathrm{p} . \mathrm{u})$ & 1.0713 & 1.0695 & 1.0552 & 1.0206 & 1.0198 & 1.1000 \\
\hline $\mathrm{V}_{2}$ (p.u) & 1.0746 & 1.0734 & 1.0577 & 1.0244 & 1.0253 & 1.1000 \\
\hline $\mathrm{V}_{3}($ p.u $)$ & 1.0603 & 1.0611 & 1.0461 & 1.0119 & 1.0155 & 1.1000 \\
\hline $\mathrm{V}_{6}(\mathrm{p} . \mathrm{u})$ & 1.0597 & 1.0594 & 1.0654 & 1.0150 & 1.0264 & 1.1000 \\
\hline $\mathrm{V}_{8}$ (p.u) & 1.0755 & 1.0778 & 1.1000 & 1.0384 & 1.0503 & 1.1000 \\
\hline $\mathrm{V}_{9}$ (p.u) & 1.0710 & 1.0699 & 1.0739 & 1.0240 & 1.0329 & 1.1000 \\
\hline $\mathrm{V}_{12}$ (p.u) & 1.0582 & 1.0562 & 1.0453 & 1.0040 & 1.0070 & 1.1000 \\
\hline $\mathrm{Qc}_{18}$ (Mvar) & 6.8293 & 4.8640 & 20.0000 & 10.8442 & 8.0117 & 0 \\
\hline $\mathrm{Qc}_{25}$ (Mvar) & 14.0936 & 16.3750 & 9.1658 & 6.4490 & 15.9809 & 15.1607 \\
\hline $\mathrm{Qc}_{53}$ (Mvar) & 11.2626 & 17.1950 & 20.0000 & 13.4479 & 11.0521 & 20.0000 \\
\hline $\mathrm{T}_{4-18}$ & 1.0432 & 0.9608 & 0.9000 & 0.9583 & 1.0192 & 0.9000 \\
\hline $\mathrm{T}_{4-18}$ & 0.9543 & 1.0416 & 1.1000 & 1.0017 & 0.9868 & 1.1000 \\
\hline $\mathrm{T}_{21-20}$ & 0.9981 & 1.0422 & 1.1000 & 0.9981 & 0.9773 & 1.1000 \\
\hline $\mathrm{T}_{24-25}$ & 1.0345 & 1.0436 & 1.1000 & 0.9680 & 0.9543 & 0.9000 \\
\hline $\mathrm{T}_{24-25}$ & 1.0039 & 1.0439 & 0.9000 & 0.9574 & 1.0740 & 1.1000 \\
\hline $\mathrm{T}_{24-26}$ & 1.0175 & 1.0326 & 1.0668 & 1.0298 & 1.0136 & 1.0171 \\
\hline $\mathrm{T}_{7-29}$ & 0.9975 & 1.0014 & 1.0565 & 0.9801 & 0.9951 & 1.0648 \\
\hline $\mathrm{T}_{34-32}$ & 0.9533 & 0.9558 & 0.9000 & 0.9283 & 0.9354 & 0.9388 \\
\hline $\mathrm{T}_{11-41}$ & 0.9016 & 0.9495 & 0.9000 & 0.9000 & 0.9001 & 0.9000 \\
\hline $\mathrm{T}_{15-45}$ & 0.9869 & 0.9883 & 0.9795 & 0.9509 & 0.9513 & 1.0178 \\
\hline $\mathrm{T}_{14-46}$ & 0.9832 & 0.9756 & 0.9796 & 0.9527 & 0.9606 & 1.1000 \\
\hline $\mathrm{T}_{10-51}$ & 0.9948 & 0.9876 & 0.9951 & 0.9725 & 0.9861 & 1.0697 \\
\hline $\mathrm{T}_{13-49}$ & 0.9579 & 0.9450 & 0.9000 & 0.9170 & 0.9177 & 0.9738 \\
\hline $\mathrm{T}_{11-43}$ & 1.0219 & 0.9863 & 1.1000 & 0.9418 & 0.9782 & 1.1000 \\
\hline $\mathrm{T}_{40-56}$ & 0.9860 & 0.9959 & 1.1000 & 1.0432 & 0.9771 & 0.9000 \\
\hline $\mathrm{T}_{39-57}$ & 0.9993 & 0.9698 & 0.9869 & 0.9218 & 0.9373 & 1.1000 \\
\hline $\mathrm{T}_{9-55}$ & 1.0120 & 1.0285 & 1.1000 & 1.0029 & 1.0128 & 1.1000 \\
\hline Fuel cost $(\$ / h)$ & 41660.2273 & $3 \quad 41673.59$ & 592241717 & 8801 & 4170 & 41791 \\
\hline VD & 1.5991 & 1.6959 & 1.7060 & 0.6940 & 0.7004 & 1.5878 \\
\hline Lmax & 0.2816 & 0.2800 & 0.2775 & 0.2931 & 0.2935 & 0.2870 \\
\hline Emission (ton/ & $\mathrm{n} / \mathrm{h}) \quad 1.3566$ & $5 \quad 1.4117$ & $7 \quad 1.3269$ & 1.3554 & 1.3507 & 1.4690 \\
\hline Ploss (MW) & 14.4929 & 14.7297 & 15.9645 & 15.7861 & $1 \quad 15.8877$ & 16.8061 \\
\hline
\end{tabular}

Table 9. The results obtained are compared for Cases 9 and10.

\begin{tabular}{rcllll}
\hline \multicolumn{1}{c}{ Case 9 } & & \multicolumn{4}{c}{ Case 10 } \\
\hline \multicolumn{1}{c}{ Algorithms } & Fuel cost $(\$ / \mathrm{h})$ & Algorithms & Fuel cost $(\$ / \mathrm{h})$ & VD $(\mathrm{p} . \mathrm{u})$ \\
\hline CS-KHA & $\mathbf{4 1 6 6 0 . 2 2 7 3}$ & CS-KHA & $\mathbf{4 1 7 1 2}$ & $\mathbf{0 . 6 9 4 0}$ \\
KHA & $\mathbf{4 1 6 7 3 . 5 9 2 2}$ & KHA & $\mathbf{4 1 7 0 5}$ & $\mathbf{0 . 7 0 0 4}$ \\
CS & $\mathbf{4 1 7 1 7 . 8 8 0 1}$ & CS & $\mathbf{4 1 7 9 1}$ & $\mathbf{1 . 5 8 7 8}$ \\
MSA [33] & 41673.7231 & MSA [33] & 41714.9851 & 0.67818 \\
ICBO [32] & 41697.3324 & FPA [33] & 41726.3758 & 0.69723 \\
\hline
\end{tabular}




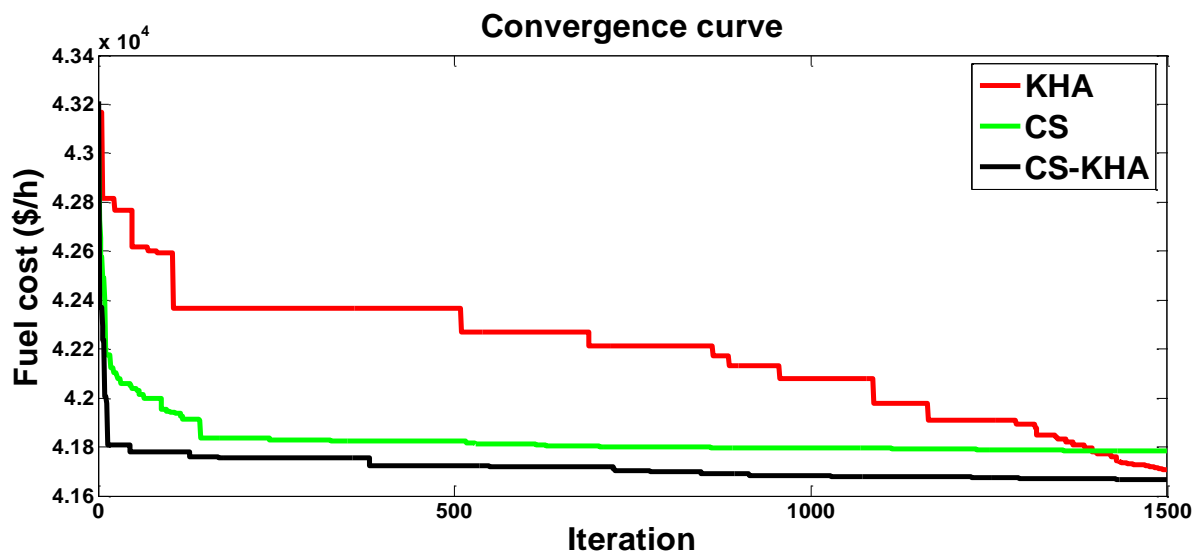

Fig.6. Convergent curves of Case 9.

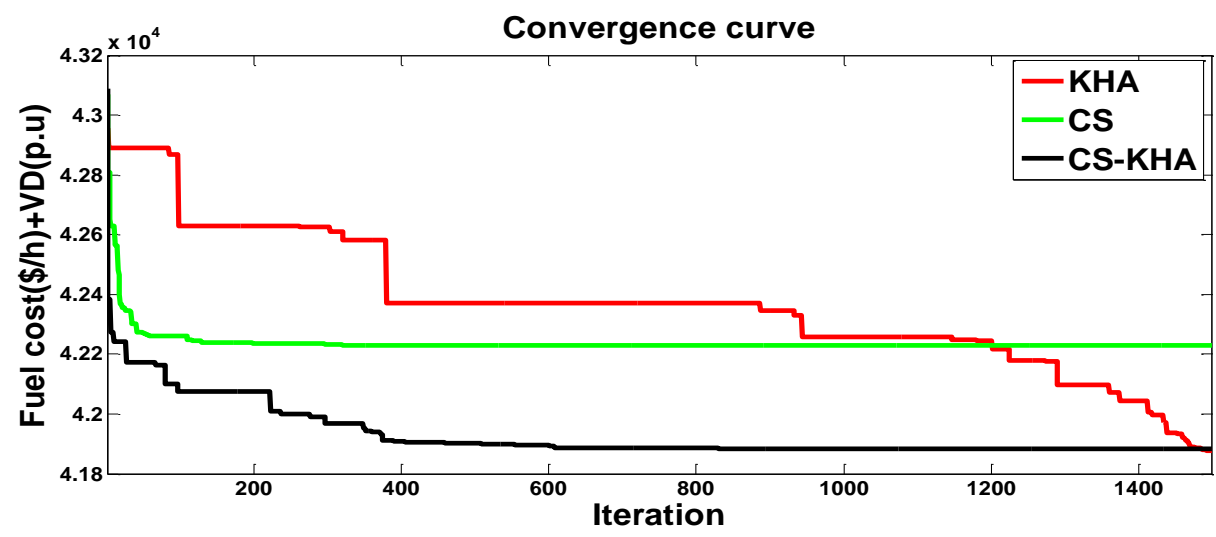

Fig.7. Convergent curves of Case 10 .

Table 10. The control variables' optimal settings for case 11.

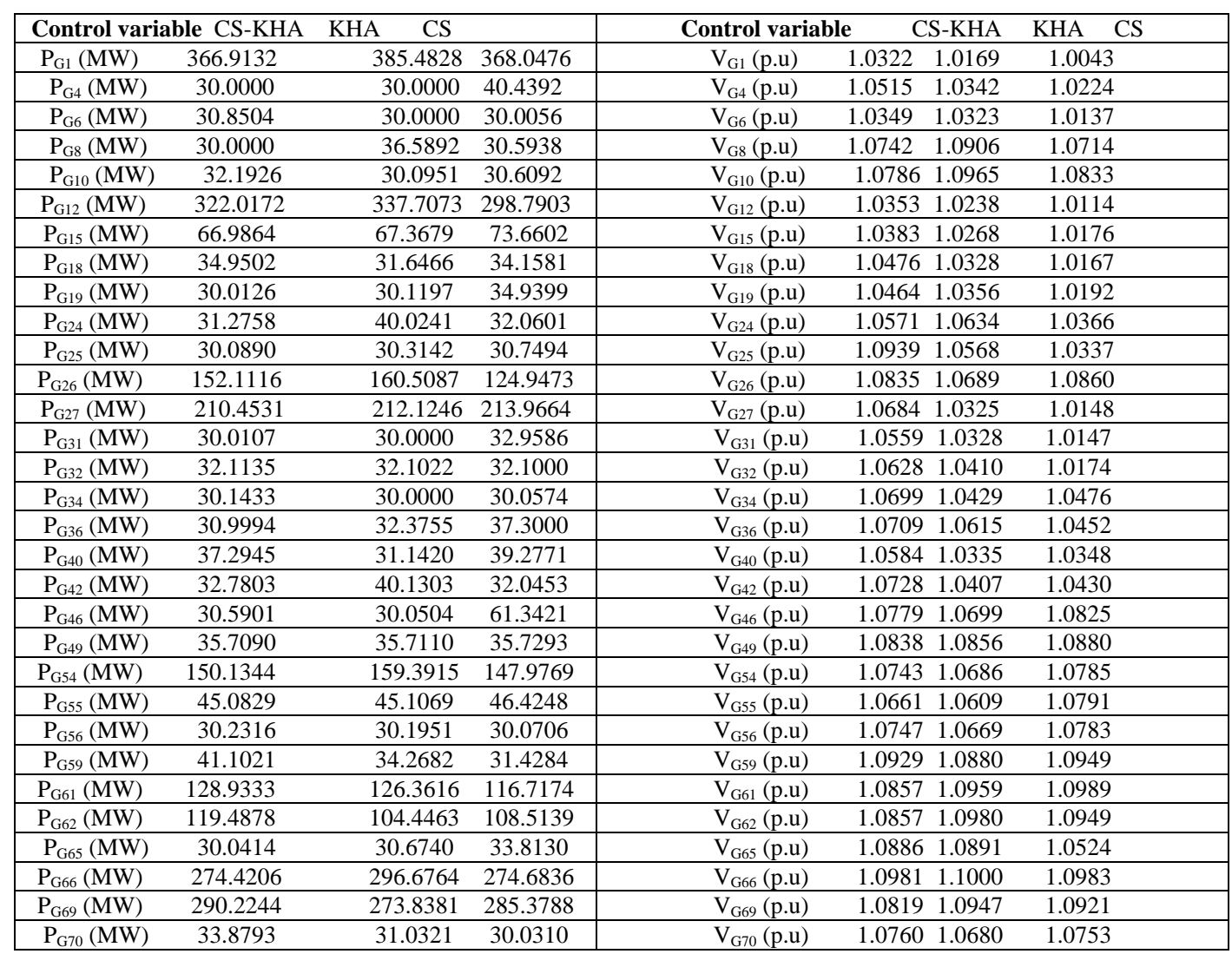




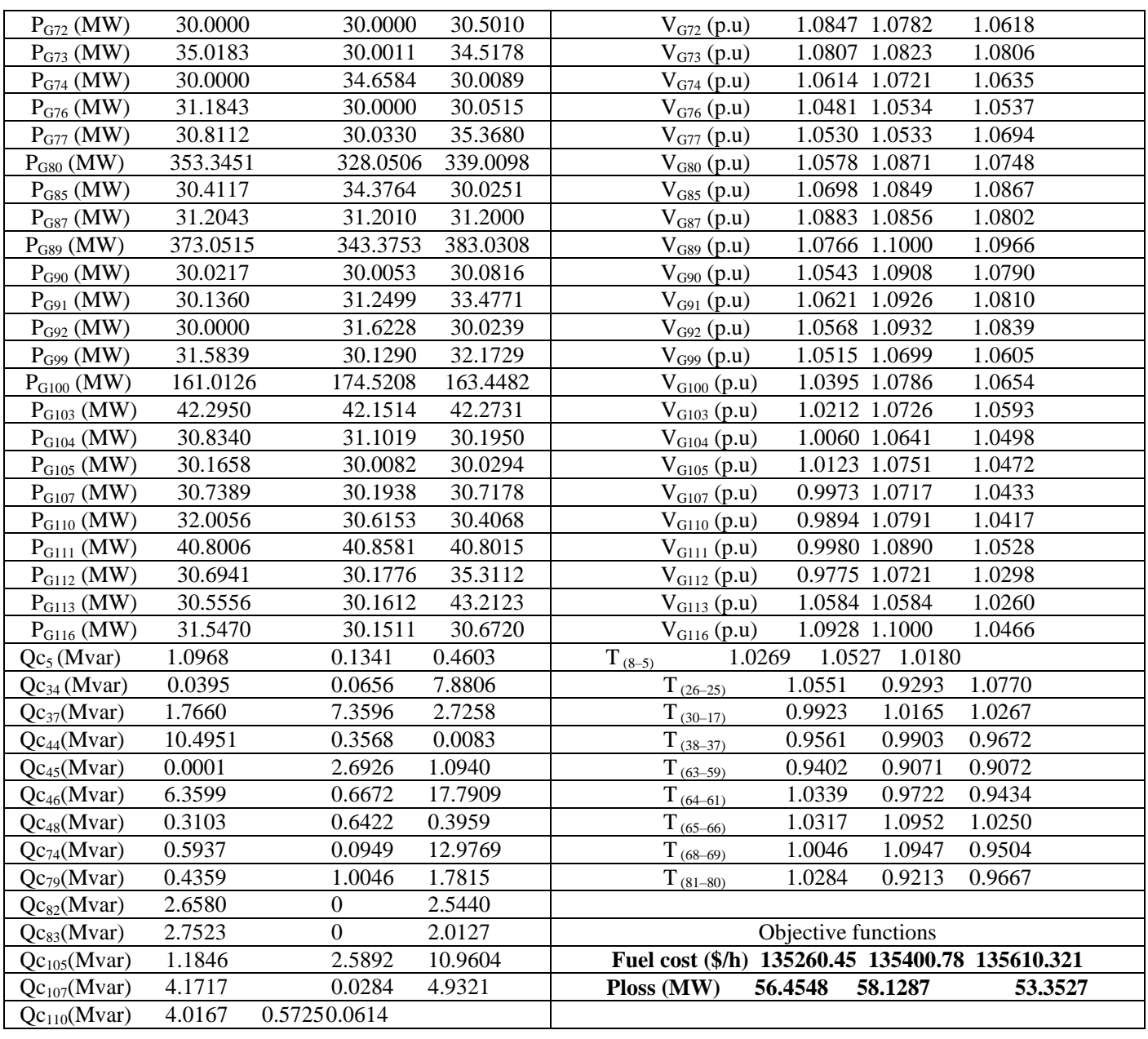

Table 11. The results obtained are compared for Case 11.

\begin{tabular}{lcc}
\hline Case & Algorithms & Fuel cost $(\$ / \mathrm{h})$ \\
\hline \multirow{4}{*}{ Case 11 } & CS-KHA & 135260.45 \\
& KHA & 135400.78 \\
& CS & 135610.321 \\
& BSA [37] & 135333.4743 \\
& ABC [37] & 135304.3584 \\
& BBO [37] & 135263.7289 \\
\hline
\end{tabular}

\section{REFERENCES}

[1] Shaheen, A.M., El-Sehiemy, R.A., Farrag, S.M., "Solving multi-objective optimal power flow problem via forced initialised differential evolution algorithm," IET Generation, Transmission and Distribution 2016, 10(7), pp. 1634-1647

[2] Huneault M, Galiana FD. A survey of the optimal power flow literature. IEEE Trans Power Syst 1991; 6(2):762-70.

[3] Chowdhury B, Rahman S. A review of recent advances in economic dispatch. IEEE Trans Power Syst 1990; 5 (4): $1248-59$.

[4] T. Niknam, M. Rasoul Narimani, M. Jabbari, A.R. Malekpour, A modified shuffle frog leaping algorithm for multi-objective optimal power flow, Energy 36 (2011) 6420-6432,

[5] Roa-Sepulveda C, Pavez-Lazo B. A solution to the optimal power flow using simulated annealing. Int $\mathbf{J}$ Electri Power Energy Syst 2003; 25:47-57.

[6] L.L. Lai \& J.T. Ma. Improved genetic algorithms for optimal power flow under both normal and contingent operation states. Electrical Power and Energy Systems, 19, 287-292, 1997.

[7] S.R. Paranjothi, K. Anburaja, Optimal power flow using refined genetic algorithm, Electr. Power Components Syst. 30 (2002) 1055-1063.

[8] Shaheen, A.M., Farrag, S.M., El-Sehiemy, R.A., "MOPF solution methodology,", IET Generation, Transmission and Distribution 2017 11(2), pp. 570-581

[9] M. Abido, Optimal power flow using Tabu search algorithm, Electric Power Syst. Res. 30 (2002) 469-483.

[10] Ghasemi M, Ghavidel S, Ghanbarian MM, Massrur HR, Gharibzadeh M. Application of imperialist competitive algorithm with its modified techniques for multi-objective optimal power flow problem: a comparative study. Inf Sci (Ny) 2014; 281:225-47.

[11] M. A. Abido, Optimal power flow using particle swarm optimization, Electrical Power and Energy Systems, 24, 563-571, 2002.

[12] A. Ramesh Kumar \& L. Premalatha, Optimal power flow for a deregulated power system using adaptive real coded biogeography-based optimization, Electrical Power and Energy Systems, 73,393-399, 2015. 
[13] P.K. Roy, S.P. Ghoshal, S.S. Thakur, Biogeography based optimization for multi-constraint optimal power flow with emission and non-smooth cost function, Expert Syst. Appl. 37 (2010) 8221-8228.

[14] Bhattacharya, A., \& Chattopadhyay, P. K. (2011). Application of biogeography-based optimization to solve different optimal power flow problems. IET generation, transmission \& distribution, 5(1), 70-80.

[15] El-Sehiemy, R.A., Shafiq, M.B., Azmy, A.M., "Multiphase search optimization algorithm for constrained optimal power flow problem," International Journal of Bio-Inspired Computation, 2014, 6(4), pp. 275-289.

[16] R. Roy \& H.T. Jadhav, Optimal power flow solution of power system incorporating stochastic wind power using Gbest guided artificial bee colony algorithm, Electrical Power and Energy Systems, 64, 562-578, 2015.

[17] A.R. Bhowmik, A.K. Chakraborty, Solution of optimal power flow using non dominated sorting multi objective opposition based gravitational search algorithm, Int. J. Electr. Power Energy Syst. 64 (2015) 1237-1250.

[18] K. Ayan, U. Kilic,, B. Baraklı, Chaotic artificial bee colony algorithm based solution of security and transient stability constrained optimal power flow, Int. J. Electr. Power Energy Syst. 64 (2015) 136-147.

[19] L. Dilip, R. Bhesdadiya, P. Jangir, Optimal Power Flow Problem Solution Using Multi-objective Grey Wolf Optimizer Algorithm, Springer Nature Singapore, Pte. Ltd. 2018.

[20] Bouchekara HREH. Optimal power flow using blackhole-based optimization approach. Appl Soft Comput J 2014; 24:879-88.

[21] Bouchekara HREH, Abido Ma, Boucherma M. Optimal power flow using teaching-learning-based optimization technique. Electr Power Syst Res 2014; 114:49-59.

[22] Attia, A.-F., El Sehiemy, R.A., Hasanien, H.M., "Optimal power flow solution in power systems using a novel SineCosine algorithm," International Journal of Electrical Power and Energy Systems, 2018, 99, pp. 331-343

[23] Daryani N, Hagh MT, Teimourzadeh S. Adaptive group search optimization algorithm for multi-objective optimal power flow problem. Appl Soft Comput 2016; 38:101224.

[24] A. Khelifi, S. Chettih, B. Bentouati, A new hybrid algorithm of particle swarm optimizer with grey wolves' optimizer for solving optimal power flow problem, Leonardo Electronic J. of P. \& Technologies. 2018, 249270.

[25] M. AlRashidi, M. El-Hawary, Applications of computational intelligence techniques for solving the revived optimal power flow problem, Electr. Power Syst. Res. 79 (2009) 694-702.

[26] A.H. Gandomi, A.H. Alavi, Krill herd: a new bio-inspired optimization algorithm, Commun. Nonlinear Sci. Numer. Simulat. 17 (2012) 4831-4845.

[27] Wang G-G, Guo L, Gandomi AH, Hao G-S, Wang H, Chaotic krill herd algorithm. Inf Sci 274 (2014) 17-34.

[28] Bentouati, B., Chettih, S., El-Sehiemy, R., "A chaotic firefly algorithm framework for non-convex economic dispatch problem," Electrotehnica, Electronica, Automatica (EEA), 2018, 66(1), pp. 172-179

[29] Xin-She Yang, Flower Pollination Algorithm for Global Optimization. In: Unconventional Computation and Natural Computation, Vol. 7445, Springer Lecture Notes in Computer Science, Berlin, Heidelberg, 2012, pp. 240 249.

[30] Ghasemia M, Taghizadeh M, Ghavidel S, Abbasian A. Colonial competitive differential evolution: an experimental study for optimal economic load dispatch. Appl Soft Comput 2016; 40:342e63.

[31] B. Mandal, P. Kumar Roy, Multi-objective optimal power flow using quasi-oppositional teaching-learning-based optimization, Appl. Soft Comput. 21(2014) 590-606.

[32] Bouchekara, H. R. E. H., Chaib, A. E., Abido, M. A., \& El-Sehiemy, R. A. (2016). Optimal power flow using an Improved Colliding Bodies Optimization algorithm. Applied Soft Computing, 42, 119-131.

[33] Mohamed, A. A. A., Mohamed, Y. S., El-Gaafary, A. A., \& Hemeida, A. M. (2017). Optimal power flow using moth swarm algorithm. Electric Power Systems Research, 142, 190-206.

[34] Bachir Bentouati et al, Optimal Power Flow using the Moth Flam Optimizer: A case study of the Algerian power system, TELKOMINIKA,.1, pp. 3. 2016.

[35] Bentouati, B., Chettih, S., El Sehiemy, R., Wang, G.-G., "Elephant herding optimization for solving non-convex optimal power flow problem," Journal of Electrical and Electronics Engineering, 201710(1), pp. 31-36

[36] Bentouati, B., Chettih, S., Djekidel, R., El-Sehiemy, R.A., "An efficient chaotic cuckoo search framework for solving non-convex optimal power flow problem," International Journal of Engineering Research in Africa, 2017, 33, pp. 84-99

[37] Chaib, A. E., Bouchekara, H. R. E. H., Mehasni, R., \& Abido, M. A. (2016). Optimal power flow with emission and non - smooth cost functions using backtracking search optimization algorithm. International Journal of Electrical Power \& Energy Systems, 81, 64-77.

[38] Wang G, Gandomi AH, Alavi AH. An effective krill herd algorithm with migration operator in biogeography-based optimization. Appl Math Model 2014; 38(9-10):2454-62.

[39] El-Hosseini, M.A., El-Sehiemy, R.A., Haikal, A.Y., "Multi-objective optimization algorithm for secure economical/emission dispatch problems," Journal of Engineering and Applied Science, 2014 61(1), pp. 83-103

[40] Biswas, P. P., Suganthan, P. N., \& Amaratunga, G. A. (2017). Optimal power flow solutions incorporating stochastic wind and solar power. Energy Conversion and Management, 148, 1194-1207.

[41] H. R. E. H. Bouchekara, Chaib, A. E., \& Abido, M. A. Optimal power flow using GA with a new multi-parent crossover considering: prohibited zones, valve-point effect, multi-fuels and emission. Electr Eng (2016).

[42] Kessel, P., \& Glavitsch, H. (1986). Estimating the voltage stability of a power system. IEEE Transactions on Power Delivery, 1(3), 346-354.

[43] R.D. Zimmerman, C.E. Murillo-Sánchez, R.J. Thomas, Matpower (Available at :) http:// www. pserc. cornell. edu/ matpower.

\section{Authors' Profiles}

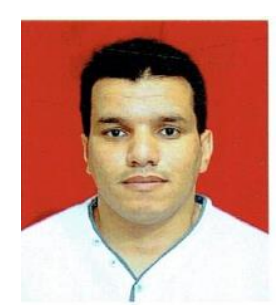

Aboubakr Khelifi was born in Laghouat (Algeria). He received master degrees in Electrical Engineering in 2015 from Amar Telidji Laghouat, University. $\mathrm{He}$ is currently a $\mathrm{PhD}$ student at the same University. His research interests are focused on the electrical power system, optimal power flow, and optimization techniques.

E-mail address: a.khelifi@lagh-univ.dz 


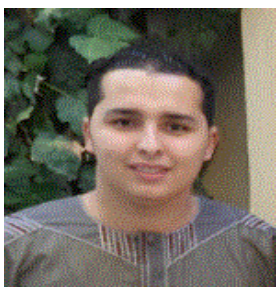

optimization techniques.

Bentouati Bachir was born in Laghouat, Algeria, on August 22, 1990. He received license, master and doctor degrees in Electrotechnic and Electrical Power System in 2010, 2012 and 2018 respectively from Laghouat university. His areas of research include optimal power flow, Artificial intelligence and

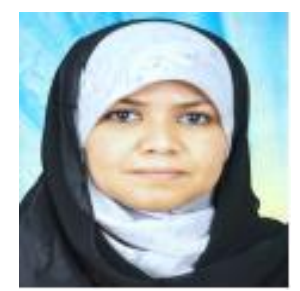

Chettih Saliha was born on 11 may 1971 in Laghouat/Algeria. She earned his $\mathrm{PhD}$ degree in Electro-technology from the University of Amar Telidji. She joined the faculty of the Technology He joined the faculty of the Technology at the University of Amar Telidji, Laghouat (Algeria), in 2008 where she is currently a professor. Her research interests optimal power flow, Artificial intelligence and optimization techniques.

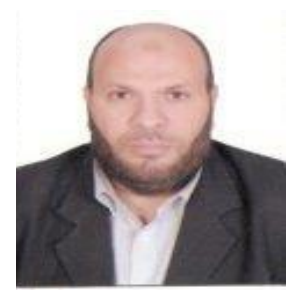

Ragab El- Sehiemy was born at Minoufiya, 1973. He received the B.Sc. M.Sc., and Ph.D. degrees in 1996, 2005, and 2008, respectively.

$\mathrm{He}$ is an Associate Professor in the Department of Electrical Engineering, Faculty of Engineering, Kafrelsheikh University, Kafr el-Sheikh, Egypt.

His research interests involve power system operation, control, and planning, applications of modern optimization techniques for variant electric power systems applications, renewable sources, and smart grid.

How to cite this paper: Aboubakr Khelifi, Bachir Bentouati, Saliha Chettih, Ragab A. El-Sehiemy, "A Novel Hybrid Method based on Krill Herd and Cuckoo Search for Optimal Power Flow Problem", International Journal of Image, Graphics and Signal Processing(IJIGSP), Vol.11, No.9, pp. 1-17, 2019.DOI: 10.5815/ijigsp.2019.09.01 